\section{Review Article}

\section{Corresponding Author}

Salman Sharif

(iD) https://orcid.org/0000-0002-3332-1789

\author{
Department of Neurosurgery, Liaquat \\ National Hospital \& Medical College, \\ Karachi 74800, Pakistan \\ E-mail: sharifsalman73@gmail.com
}

Received: June 14, 2020

Revised: September 14, 2020

Accepted: September 14, 2020

\title{
Subaxial Cervical Spine Injuries: WFNS Spine Committee Recommendations
}

\author{
Salman Sharif ${ }^{1}$, Muhammad Yassar Jazaib Ali' ${ }^{1}$, Ibet Marie Y. Sih², Jutty Parthiban ${ }^{3}$, \\ Óscar L. Alves ${ }^{4}$ \\ ${ }^{1}$ Department of Neurosurgery, Liaquat National Hospital \& Medical College, Karachi, Pakistan \\ ${ }^{2}$ Institute for the Neurosciences, St. Luke's Medical Center, University of the Philippines - Philippine General \\ Hospital, Metro Manila, The Philippines \\ ${ }^{3}$ Department Neurosurgery and Spine Unit, Kovai Medical Center and Hospital, Coimbatore, India \\ ${ }^{4}$ Department of Neurosurgery, Hospital Lusíadas, Porto, Portugal
}

To formulate specific guidelines for the recommendation of subaxial cervical spine injuries concerning classification, management, posttraumatic locked facets and vertebral artery injury. Computerized literature was searched on PubMed and google scholar database from 2009 to 2020. For classification, keywords "Sub Axial Cervical Spine Classification," resulting in 22 articles related to subaxial cervical spine injury classification system (SLICS) system and 11 articles related to $\mathrm{AO}$ (Arbeitsgemeinschaft für Osteosynthesefragen, German for "Association for the Study of Internal Fixation") Spine system. The literature search yielded 210 and 78 articles on "management of subaxial cervical spine injuries" and the role of "SLICS" and "AO Spine" respectively. Keywords "management of traumatic facet locks" were searched and closed reduction, traction, approaches and techniques were studied. "Vertebral artery injury and cervical fracture" exhibited 2,328 references from the last 15 years. The objective was to identify the appropriate diagnostic tests and optimal treatment. Up-todate information was reviewed, and statements were produced to reach a consensus in 2 separate consensus meetings of World Federation of Neurosurgical Societies (WFNS) Spine Committee. The statements were voted and reached a positive or negative consensus using Delphi method. Based on the most relevant literature, panelists in Moscow consensus meeting conducted in May 2019 drafted the statements, and after a preliminary voting session, the consensus was identified on various statements. Another meeting was conducted at Peshawar in November 2019, where in addition to previous statements, few other statements were discussed and voted. Specific recommendations were then formulated guiding classification, management, locked facets and vertebral artery injuries. This review summarizes the WFNS Spine Committee recommendations on subaxial cervical spine injuries.

Keywords: Subaxial cervical spine, AO Spine, Subaxial cervical spine injury classification system, Classification and management, Locked facet, Vertebral artery injury
Copyright $\odot 2020$ by the Korean Spinal Neurosurgery Society the terms of the Creative Commons Attribution Non-Commercial License (https://creativecom unrestricted non-commercial use, distribution, and reproduction in any medium, provided the original work is properly cited.

\section{INTRODUCTION}

The subaxial spine is a common site of cervical injury, with more than $50 \%$ of injuries being located between the C5 and C7 region. ${ }^{1}$ The substantial motion of the cervical spine is what predisposes it to injury or instability. Devastating sequelae of subaxial cervical spine trauma include tetraplegia, functional loss, and permanent disability; therefore, a consistent algorithm for diagnosis and management of these injuries is paramount.

The treatment of spine trauma management is historically based on anecdotal rather than system-based practices, often dictated by institutional, regional, and individual surgeon preferences. The sparsity of a universally accepted classification system is one of the major reasons behind this practice. Further- 
more, the optimal treatment strategy of subaxial cervical spine injuries is still under debate, and research is underway on the most appropriate treatment algorithm for a specific type of subaxial cervical spine injury. ${ }^{1,2}$ Within the literature, only a few studies with a high level of evidence are available on the surgical treatment of traumatic subaxial spine injuries. In addition to various mechanisms of injury, the involvement of facets in the cervical spine is a fascinating subject that is discussed here. The injuries involving the subaxial cervical spine demand a special focus on the vascular injury to the vertebral artery. Vertebral artery injury (VAI) with cervical fractures in blunt trauma mandates specific guidelines for these special cases. ${ }^{3}$

\section{CLASSIFICATION OF SUBAXIAL CERVICAL SPINE INJURIES}

\section{Materials and Methods}

Literature was searched from 2009 to 2020 on the safety and effectiveness of current classification systems in guiding the treatment of subaxial cervical spine injury. Using the keywords "Subaxial Cervical Spine Classification," Google scholar database resulted in 3,790 hits. On refining the search terms and removing non-English articles, 560 articles were shortlisted. Of these, 19 articles that dealt with specific management protocols of subaxial cervical spine injuries were identified and studied. The studies that dealt with axial cervical spine injuries or thoracolumbar injuries were excluded. A literature search on the PubMed database with the keywords mentioned above resulted in 123 hits, which were shortlisted to 49 studiesafterthe exclusion of non-English articles.

\section{Results}

A total of 32 articles from both databases that dealt explicitly with the classification system of subaxial spine injuries, their reliability and validity were chosen. Twenty-two articles related to the subaxial cervical spine injury classification system (SLICS) and 10 articles to the $\mathrm{AO}$ (Arbeitsgemeinschaft für Osteosynthesefragen, German for "Association for the Study of Internal Fixation") Spine system were selected and studied (Fig. 1). Based on the most relevant literature, drafted statements were voted by panelists in Moscow consensus meeting in May, followed by Peshawar in November 2019.

Modified AO Spine system, that was not included in the above consensus. The systematic review suggests that the AO Spine SLICS demonstrated considerable reliability in this initial assessment.

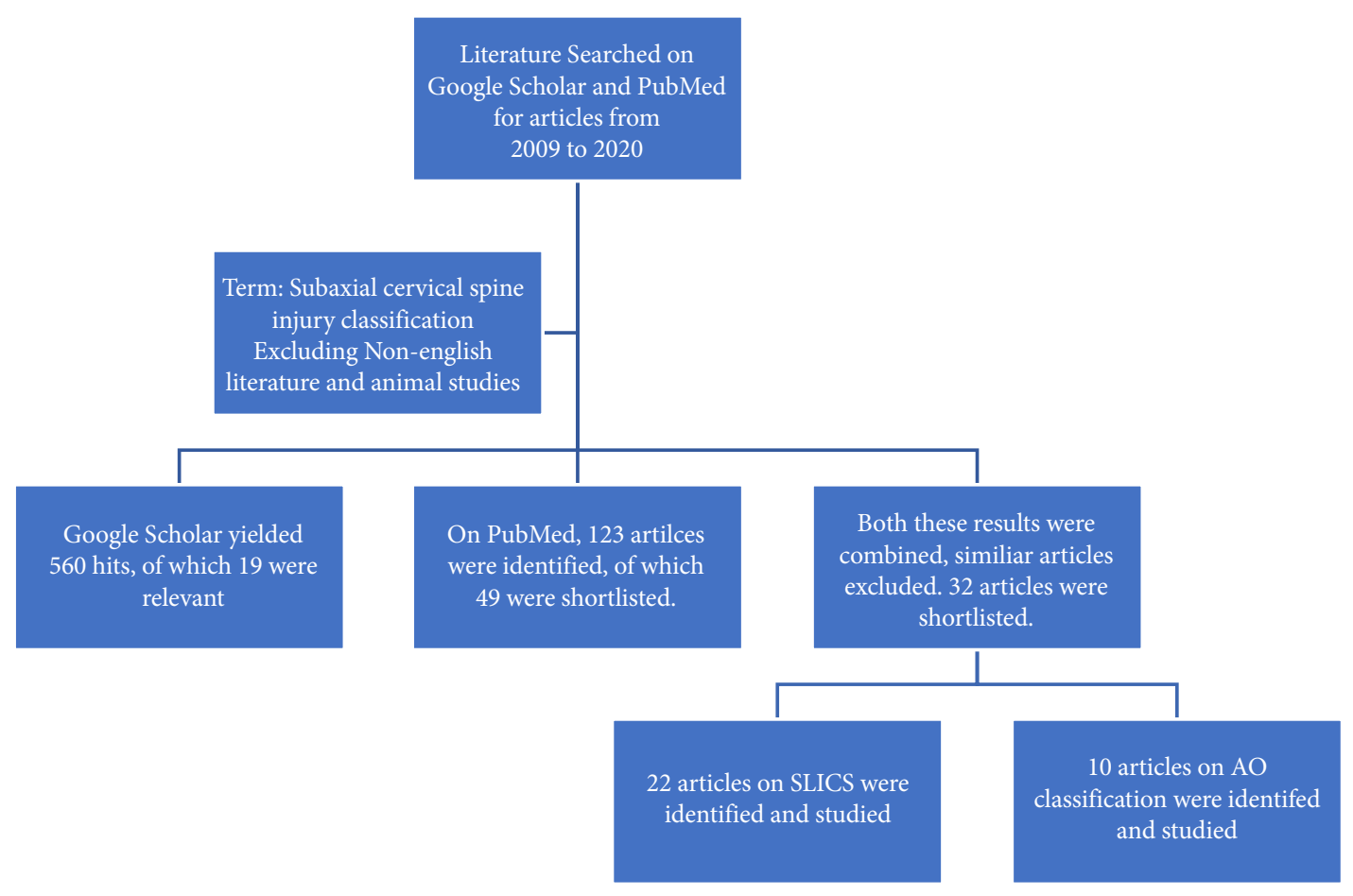

Fig. 1. literature search for classification system of subaxial cervical spine injury. SLICS, subaxial cervical spine injury classification system; AO, Arbeitsgemeinschaft für Osteosynthesefragen (German for "Association for the Study of Internal Fixation"). 


\section{Discussion}

A successful classification system enables communication and agreement between physicians, determines the severity of the injury, and guides prognosis and treatment guidelines. There is a clear need to improve current classification and reach an agreement on a universally accepted classification system that is easily applicable, reproducible, reliable, and clinically validated.

Allen et al. ${ }^{4}$ developed the first mechanical classification for the subaxial cervical spine based on 6 mechanisms of injury. Difficulty in clinical application, and lack of significant interobserver reliability were the problems with this system. ${ }^{5}$ Harris et al. ${ }^{6}$ proposed his mechanical classification with 7 main categories and several subgroups; however, the clinical use of this system was also limited. The SLICS was created by the Spine Trauma Study Group in 2007 by incorporating previous systems to guide the management of subaxial injuries. This has been revised by including patient factors. ${ }^{7,8}$ The Cervical Spine Injury Severity Score (CSISS) is another classification system that has been used over the years. CSISS divides the subaxial cervical spine into 4 columns, anterior, posterior, and 2 lateral pillars, and adds up the injuries to all columns. However, unlike the subaxial cervical spine injury classification (SLIC), lack of neurologic status limits its applicability. ${ }^{9,10}$ The AOSpine Knowledge Forum Trauma group has also developed a unified classification system for the entire spinal column, including the subaxial cervical spine. ${ }^{11}$

\section{Subaxial Cervical Spine Injury Classification System}

The Spine Trauma Study Group in 2007 developed an evidence-based algorithm to help in deciding which patients need surgery. The SLIC scoring system can guide whether surgical or nonsurgical treatment should be undertaken based on the score achieved. Three main categories, i.e., the morphology of injury, integrity of disco-ligamentous complex (DLC), and neurological status, were found to be integrally crucial to the description of injury, treatment, and prognosis. Injuries with a score of 5 or more are all treated surgically, while those scoring 3 or less are treated nonsurgically, with a score of 4 being considered equivocal. SLIC severity scale abandons the traditional characteristics of the mechanism of injury and anatomy in favor of injury's morphology and neurologic status (Fig. 2). ${ }^{12}$

Interrater agreement, as measured by intraclass correlation coefficient (ICC) of the DLC, morphology, and neurological status components, was $0.49,0.57$, and 0.87 , respectively. The intrarater agreement, as determined by ICC of the DLC, morphology, and neurological status scores, was $0.66,0.75$, and 0.90 , respectively. High validity of construct was suggested by rater agreeing with treatment recommendations of the algorithm in 93.3\% of cases. Interobserver and intraobserver reliability were assessed for SLICS by comparing with the earlier Ferguson and Allen, and Harris system. The SLIC does not assist in the choice of surgical approach. The authors proposed an algorithm to guide the selection of surgical procedures by using the categories of burst, distraction, and translation (Table 1). ${ }^{2,12}$

\section{Reliability and Validity of SLICS Classification System}

SLICS is the most widely used classification system that helps in predicting the prognosis. ${ }^{13}$ Most studies have shown that SLICS is both reproducible and reliable. Aarabi et al. ${ }^{7}$ in 2013, recommended SLIC as the ideal classification system for spinal cord injury. The overall interrater reliability of SLIC has an ICC of 0.71 (level 1 evidence). On the other hand, the CSISS was recommended for graded instability and fracture patterns in patients with spinal cord injury. Even with excellent reliability, the system was identified to be complicated, and its use was limited to clinical trials (level 1 evidence). The Harris classification of subaxial spinal injury was not recommended due to its low reliability (ICC of 0.42) (level 3 evidence), The Allen classification is not recommended for describing the mechanical and radiographic findings in the cervical cord injury due to its low reliability (ICC of 0.53) (level 3 evidence). SLICS and CSISS were identified to be reliable overall with level 1 evidence. Internal

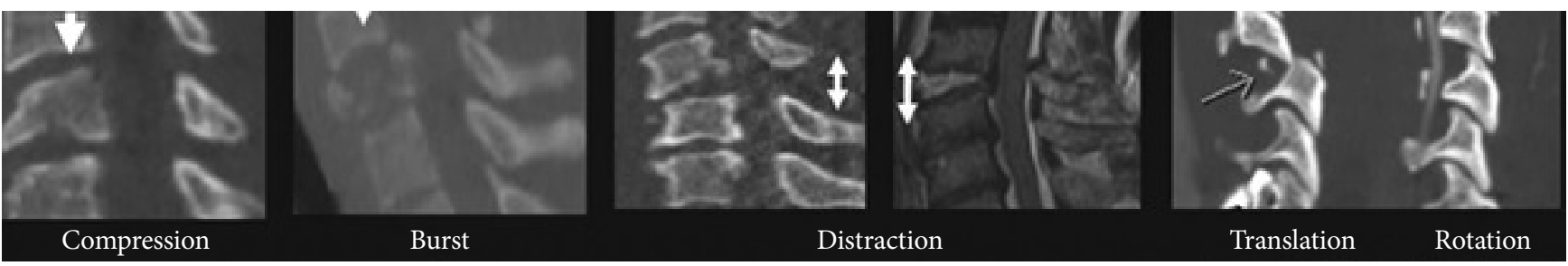

Fig. 2. Sagittal views of computed tomography and magnetic resonance imaging depicting the 4 components of morphology in the subaxial cervical spine injury classification and severity scale. (Permission taken from corresponding author and publisher Wolters Kluwer).? 
Table 1. Subaxial cervical spine injury classification scale

\begin{tabular}{lc}
\hline Category & Point \\
\hline Morphology & 0 \\
No abnormality & 1 \\
Compression & $+1=2$ \\
Burst & 3 \\
Distraction (facet perch, hyperextension) & 4 \\
Rotation/translation & \\
Disco-ligamentous complex & 0 \\
Intact & 1 \\
Indeterminate (isolated interspinous widening, MRI & \\
$\quad$ signal change only) & 2 \\
Disrupted (widening of disc space, facet perch, & \\
$\quad$ or dislocation) & \\
Neurological status & \\
Intact & \\
Root Injury & \\
Complete cord injury & \\
Incomplete cord injury & 1 \\
Continuous cord compression (NeuroModifier) & +1 \\
\hline
\end{tabular}

MRI, magnetic resonance imaging.

consistency for both SLICS and CSISS was indicated by the worsening of score reflecting worse injury.

da Cruz et al. ${ }^{14}$ published his results in 2015 by comparing a cohort of surgically treated patients who underwent surgery on the surgeon's preference, with those who underwent surgery based on the SLICS score. Two patients had the SLICS of less than 4 points. Group 2 had a total of 28 patients with a mean SLICS score of 6 . There was no neurological deterioration in any group. They concluded that by incorporating the SLICS, there was a decrease in the number of patients with less severe injuries undergoing surgical treatment. SLICS improved their results of treatment by distinguishing mild forms of injury from the severe ones. SLICS may help surgeons with the standardization of care as well as with the choice of more unstable patterns for surgical treatment. ${ }^{14}$

Joaquim et al., ${ }^{15}$ in a retrospective study, demonstrated that there was more than $90 \%$ agreement between the SLIC score and treatment algorithm chosen by the surgeon. Stone et al. ${ }^{5}$ compared the interobserver and intraobserver reliability of the CSISS, the subaxial injury classification (SLIC) and severity scale, and the Allen-Ferguson (AF) system system in patients with subaxial cervical spine injuries. In this study, 5 examiners independently reviewed c-spine radiology (computed tomography/
Table 2. Agreement between AF and SLIC based on Landis and Koch criteria

\begin{tabular}{lcc}
\hline & Interrater agreement & Intrarater agreement \\
\hline AF & Moderate & Moderate \\
Morphology & Fair & Moderate \\
SLIC DLC & Fair & Fair \\
SLIC neurology & Fair & Substantial \\
SLIC total & Slight & Fair \\
\hline
\end{tabular}

AF, Allen-Ferguson system; SLIC, subaxial cervical spine injury classification; DLC, disco-ligamentous complex.

magnetic resonance imaging [CT/MRI]) of 50 consecutive patients with subaxial cervical spine injuries seen in the Emergency Department over 5 months and classified each case using CSISS, SLIC, and the AF system. Examiners also documented that if surgical management was required in their opinion or not. After 6 weeks, the above steps were repeated for 10 randomly chosen cases. ${ }^{5}$ They concluded that the interobserver and intraobserver reliability for the total CSISS and total SLIC score are excellent, whereas poor interobserver reliability and excellent intraobserver reliability for the AF system. Concerning surgical management decisions, the interobserver agreement is moderate, and intraobserver agreement is excellent. Good intraobserver and interobserver agreement was observed among surgeons calculating a SLIC score (0.79 and 0.98 for total SLIC score, respectively). ${ }^{16-18}$

The drawback is that most of these studies are retrospective, and prospective data are sparse. Poor intraobserver rating concerning morphological classification has been explained with some of the more recent studies, with only average agreement on the integrity of the DLC. van Middendorp et al. ${ }^{18}$ also identified that interobserver agreement concerning treatment choice based on SLIC scoring was lower than agreement based on personal surgeon preference. Indeterminate assessment of DLC with a score of 1 can be a source of inconsistency with surgical planning, and the low specificity of MRI can lead to false-positive findings of DLC disruption. This may lead to an unnecessarily elevated SLIC score and unindicated surgery. ${ }^{18}$ Feuchtbaum et al., ${ }^{19}$ in his review, presented that poor interobserver reliability is the defining pitfall of this tool and proposed the use of amended classification systems to improve interobserver reliability. Large scale studies are needed for a more definitive evaluation of subaxial cervical spinal injury.

A psychometrics study was conducted to determine the intraobserver and interobserver reliability of the AF system and subaxial injury classification and severity scale. This study iden- 
Table 3. Comparision of subaxial trauma classification systems

\begin{tabular}{lccc}
\hline Classification system & Reliability & $\begin{array}{c}\text { Implications for } \\
\text { management }\end{array}$ & Complexity \\
\hline Vaccaro et al. $^{12}$ (SLIC) & Yes & Yes & Low \\
Allen et al. ${ }^{4}$ & No & No & Low \\
Harris et al. $^{6}$ & No & No & High \\
Anderson et al. $^{10}$ & Yes & Yes & High
\end{tabular}

SLIC, subaxial cervical spine injury classification.

tified that the AF system displayed a uniformly moderate inter and intraobserver reliability. SLIC showed slight to fair interobserver reliability and fair to substantial intraobserver reliability (Tables 2, 3). ${ }^{20}$

Dvorak et al. ${ }^{2}$ provide a set of comprehensive recommendations, concluding that the SLIC system had been developed to address the shortcomings of previous classifications. The SLIC system provides diagnostic information and can guide surgical versus nonsurgical treatment. ${ }^{21}$

Samuel et al. ${ }^{22}$ presented his results from a retrospective case series conducted in a consecutive series of 185 patients with subaxial cervical spine trauma presenting to a level 1 spinal injury center to test the validity of subaxial injury classification and treatment recommendations. Surgeon responsible for treatment decision, treatment received, and surgical approach was documented. Treatment received corresponded to SLIC guidelines in $93.6 \%$ of nonsurgically managed patients and $96.3 \%$ of surgically managed patients. The mean SLIC score of the group of patients undergoing surgical treatment was significantly higher than that of the nonsurgical group (7.14 vs. 2.22, p <0.001). Sixty-six patients had a SLIC score of 3 or less, and $94 \%$ of them were nonsurgically managed $(\mathrm{p}<0.001)$. One hundred 2 patients had a SLIC score of 5 or more, and $95 \%$ of them were surgically managed $(\mathrm{p}<0.001)$. Seventeen patients had a SLIC score of 4 , and $65 \%$ were nonsurgically managed $(p=0.032)$. The practice of these 7 fellowship-trained spine surgeons was individually in agreement with SLIC treatment recommendations. They found that the use of SLIC as an ordinal severity scale is validated as increasing SLIC scores correlated with the increasing complexity of treatment. The injury morphology score could not predict a surgical approach. Significantly higher numbers of patients with a SLIC score of 4 were treated nonsurgically. ${ }^{22}$

Hitti et al..$^{8}$ conducted a retrospective review on patients presenting with acute subaxial cervical spine injury between 2007 and 2016. Hitti and colleagues assessed the predictors of failure of nonoperative management. Forty patients were included with a
Table 4. Modified subaxial cervical spine injury classification

\begin{tabular}{lc}
\hline Characteristic & Points \\
\hline Morphology & 0 \\
Abnormality & 1 \\
Compression & 2 \\
Burst & 3 \\
Distraction & 4 \\
Rotation/translation & \\
Diskoligamentous complex & 0 \\
Intact & 1 \\
Intermediate & 2 \\
Disrupted & \\
Neurological status & 0 \\
Intact & 1 \\
Root Injury & 2 \\
Complete cord injury & 3 \\
Incomplete cord injury & \\
Ongoing cord compression & 1 \\
Time to stabilization (hr) & +1 \\
$<8$ & \\
$>24$ & \\
Osteoporosis & \\
\hline & \\
\hline
\end{tabular}

small subset failing nonoperative management $(n=5,12.5 \%)$. Evaluation within 8 hours of injury was a negative predictor of failure (odds ratio, $0.03 ; \mathrm{p}=0.001$ ) and evaluation 24 hours or more after injury was a positive predictor of failure (odds ratio, 66.00; $\mathrm{p}<0.001$ ). They presented a modified SLIC score based on these findings, which significantly predicted the failure of nonoperative management $(p=0.044)$. Delay in time to stabilize may increase the likelihood of treatment failure. Limitations of the study included the retrospective nature of the study, small sample size from a single-center, resulting in sampling bias (Table 4). ${ }^{8}$

\section{AO Classification System for Subaxial Cervical Spinal Injury}

The AOSpine Knowledge Forum in 2013 developed a comprehensive and feasible spinal trauma classification system. The Classification divided the spinal column into 4 regions: the upper cervical spine (till C2), subaxial cervical spine (C3-7), thoracolumbar spine (T1-L5), and the sacral spine (S1-5, with coccyx). A hierarchical system is used to classify each region with increasing levels of injury or instability and represents the morphology of the injury, neurologic status, and clinical modifiers. 
Morphologic classification is based on radiologic exams and described separately for different regions. Fractures are classified into compression injuries (A), tension band injuries (B), and translational injuries $(\mathrm{C})$, with additional descriptions for facet injuries. Neurological status is graded according to a 5-part system. Patient-specific modifiers in the AOSpine Trauma Classification highlight unique clinical characteristics for each injury and facilitate communication, treatment, and prediction of prognosis between surgeons. Modifiers are denoted starting with $\mathrm{M}$ followed by a number. Each number describes a different type of injury and does not correlate with increasing severity (Fig. 3A-C). ${ }^{11,23-25}$

Interobserver reliability was substantial for all injury subtypes ( $j=0.75$ and 0.64 , respectively). The AO Spine SLICS demonstrated significant reliability in this initial assessment and could be a valuable tool for communication, patient care, and for research purposes. ${ }^{26}$

\section{Type A Compression Injuries}

\section{$\triangle \bigcirc$ Minor, nonstructural fractures} No bony injury or minor injury such as an isolated lamina fracture or spinous process fracture.
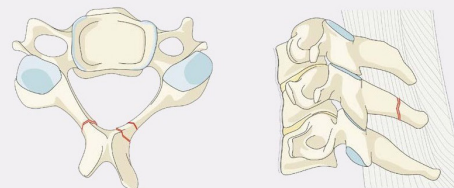

A1 Wedge-compression Compression fracture involving a single endplate without involvement of the posterior wall of the vertebral body.

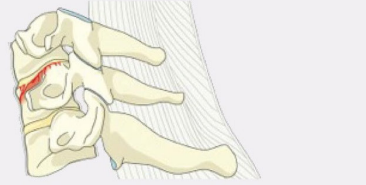

\section{A2 spli}

Coronal split or pincer fracture involving both endplates without involvement of the posterior wall of the vertebral body.

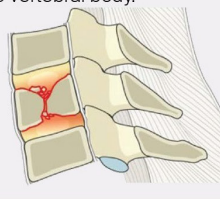

\section{A3 Incomplete burst \\ single endplate with} involvement of the posterior vertebral wall.
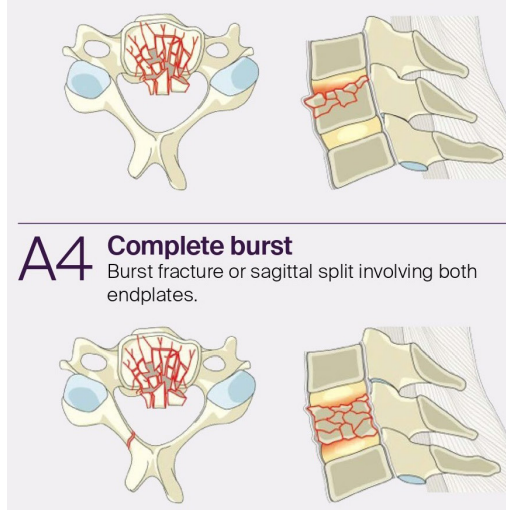

Type B Tension Band Injuries

B1 Posterior tension band injury (bony) Physical separation through fractured bony structures only.
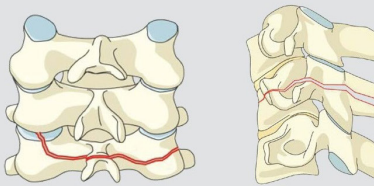

\section{B2}

Posterior tension band injury (bony capsuloligamentous, ligamentous) Complete disruption of the posterior capsuloligamentous or bony capsuloligamentous structures together with a vertebral body, disk, and/ or facet injury.

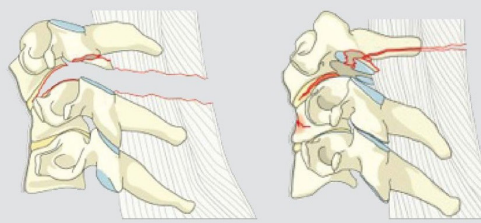

\section{B3 Anterior tension band injury} structures (bone/disk) with tethering of the pos elements.

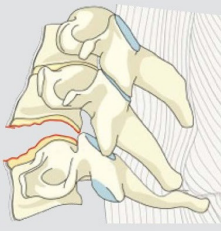

\section{BL Bilateral Injuries}

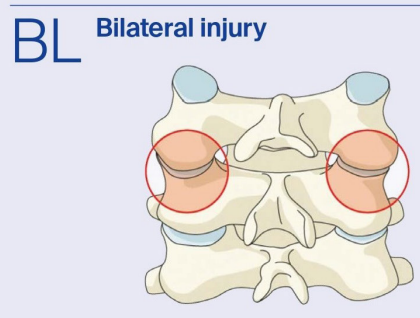

Type C Translation Injuries

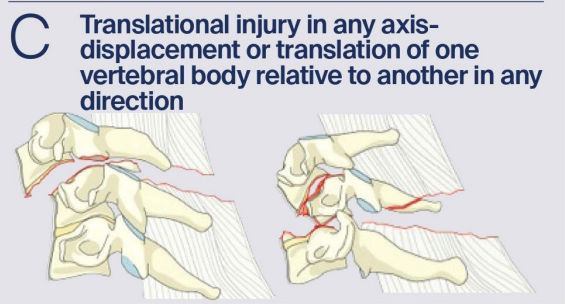

\section{Type F Facet Injuries}

-1 Nondisplaced facet fracture

With fragment $<1 \mathrm{~cm}$ in height, $<40 \%$ of lateral mass.
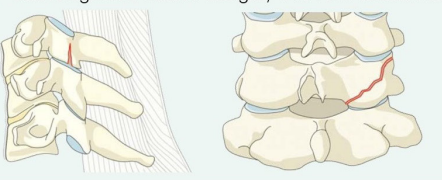

E Facet fracture with potential for instability With fragment $>1 \mathrm{~cm}$, $>$ than $40 \%$ lateral mass, or displaced.
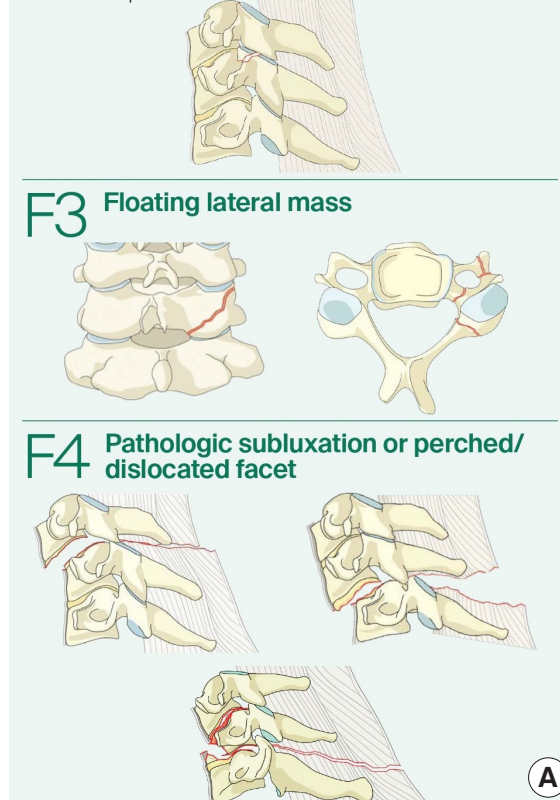

Fig. 3. AO spine classification system for subaxial cervical spine injuries (@AO Foundation, AO Spine, Switzerland). ${ }^{23-26,32}$ (A) Morphological classification of AO Spine.

(Continued to the next page) 


\section{Algorithm for morphologic classification}

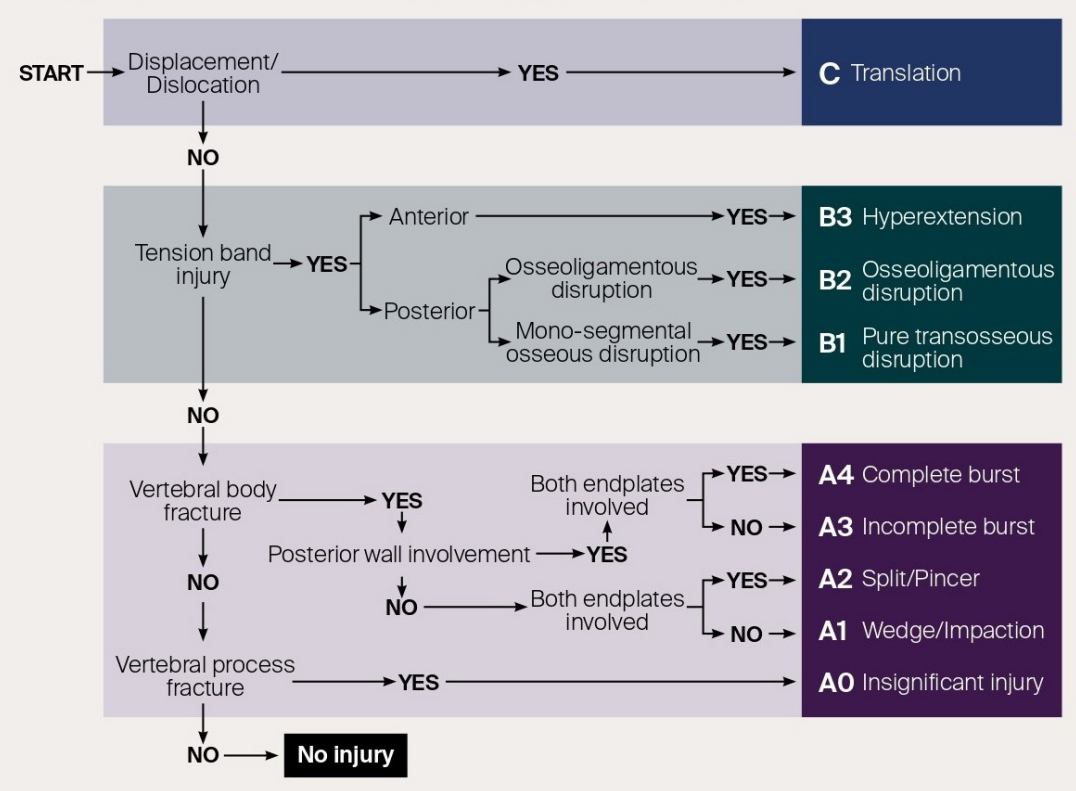

(B)

Neurology
\begin{tabular}{|c|l|}
\hline Type & Neurological \\
\hline No & Neurology intact \\
\hline N1 & Transient neurologic deficit \\
\hline N2 & Radicular symptoms \\
\hline N3 & $\begin{array}{l}\text { Incomplete spinal cord injury or } \\
\text { any degree of cauda equina injury }\end{array}$ \\
\hline N4 & Complete spinal cord injuryl \\
\hline NX & Cannot be examined \\
\hline+ & Continued spinal cord compression \\
\hline
\end{tabular}

\section{Modifiers}

\begin{tabular}{|l|l|}
\hline Type & Description \\
\hline M1 & Posterior Capsuloligamentous Complex injury without complete disruption. \\
\hline M2 & Critical disk herniation. \\
\hline M3 & Stiffening/metabolic bone disease (ie DISH, AS, OPLL, OLF). \\
\hline & \\
\hline M4 & Vertebral artery abnormality. \\
\hline
\end{tabular}

\section{Classification Nomenclature}

C6-C7 translation injury (C)
with a $\mathrm{C7}$ compression fracture (A1)

C6-C7: C

(C7: A1)

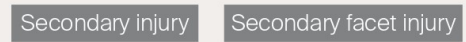$$
\text { L }
$$

L

(F4; F2; $\underline{\text { N2, M3) }}$

"If there are multiple injuries to the same facet - for example: small fracture (F1) and dislocation (F4) -,

"IIf only facet injuries are identified - no A, B, or C injury -, they are listed first after the level of injury.

Fig. 3. (Continued) (B) Algorithm for classifying injuries, and (C) Neurology and Modifiers.

\section{1) AO spine classification validity and reliability}

Da Silva et al. ${ }^{27}$ evaluated the AOSpine group's classification for subaxial cervical spinal trauma via a retrospective study that used SLIC for dividing patients into the conservative and surgical management group. Five different blinded researchers classified patients' injuries according to the AOSpine system using CT imaging at 2 different times with a 4 -week interval. Reliabil- ity was assessed using the kappa index (k), while validity was inferred by comparing the classification obtained with the treatment performed. Fifty-one patients were included: 31 underwent a surgical procedure, and 20 were managed nonsurgically. Intraobserver agreement for subgroups ranged from 0.61 to 0.93 , and interobserver agreement was 0.51 (first assessment) and 0.6 (second assessment). Intraobserver agreement for groups 
ranged from 0.66 to 0.95 , and interobserver agreement was 0.52 (first assessment) and 0.63 (second assessment). The kappa index in all evaluations was 0.67 for type $\mathrm{A}, 0.08$ for type $\mathrm{B}$, and 0.68 for type $\mathrm{C}$ injuries, and for the facet modifier, it was 0.33 (F1), 0.4 (F2), 0.56 (F3), and 0.75 (F4). Complete agreement for all components was attained in 25 cases (49\%) (19 type A and 6 type C), and for subgroups, it was achieved in 22 cases (43.1\%) (16 type A0 and 6 type C). Type A0 injuries were treated conservatively or surgically according to their neurological status and ligamentous status. Type $\mathrm{C}$ injuries were treated surgically in almost all cases, except one. AO Spine Classification demonstrates good statistical agreement for group (types A, B, and C) classification. Limitations of the study were a single-center retrospective study, unable to guide treatment alone, low agreement rate for intermediate morphology (types A1-4 and B), and facet modifiers were imprecise. They suggested intensive prospective investigations. ${ }^{27}$

Aarabi et al. ${ }^{28}$ retrospectively analyzed the prospectively collected data on clinical, imaging, management, and ASIA Impairment Scale (AIS) grade conversion of 92 AIS grades A-C patients with a cervical spine injury. All patients had surgical intervention for decompression and internal fixation. The operating neurosurgeon decided the specific surgical procedure to be used. The morphology was correlated with age, intramedullary lesion length (IMLL), injury severity score, follow-up ASIA motor score (AMS), and AIS grade conversion at 6 months after injury. The mean AMS was 17.1. At a 6 months follow-up, the mean AMS was 39.6. Compared to patients with $\mathrm{cl}$ ass B3 injuries, those with class $\mathrm{C}$ injuries were significantly younger $(\mathrm{p}=0.0001)$, had longer IMLL $(\mathrm{p}=0.002)$, and were less likely to have AIS grade conversion to a better grade $(p=0.02)$. The AOSpine system successfully predicted injury severity (longer IMLL) and chances of neurologic recovery (AIS grade conversion) across different class subtypes. Intrarater and interrater reliably among surgeons, indicate injury severity, guide surgery, and predict the outcome. Compared with other morphologic classifications, the AO Spine subaxial cervical injury classification meets all those objectives. This classification will be helpful in future prospective, comparative, and randomized trials. ${ }^{28}$

Urrutia et al..$^{29}$ compared AOSpine and AF classifications to determine which system allows better agreement. Complete imaging studies of 65 patients with subaxial cervical spine injuries were classified by 6 evaluators using the AOSpine subaxial cervical spine classification system and the AF scheme. The AOSpine classification allows a significantly better agreement than the AF classification. Table 5 depicts the agreement on the
Table 5. Agreement for existing classification systems of subaxial cervical spine injuries

\begin{tabular}{|c|c|c|c|c|}
\hline \multirow{2}{*}{ Study } & \multicolumn{2}{|c|}{ Interobserver } & \multicolumn{2}{|c|}{ Intraobserver } \\
\hline & Kappa & ICC & Kappa & ICC \\
\hline \multicolumn{5}{|l|}{ Allen and Ferguson } \\
\hline Stone et al. ${ }^{5}$ & 0.50 & & 0.91 & \\
\hline Vaccaro et al. ${ }^{12}$ & 0.53 & & 0.63 & \\
\hline \multicolumn{5}{|l|}{ CSISS } \\
\hline Stone et al. ${ }^{5}$ & & 0.96 & & 0.98 \\
\hline Anderson et al. ${ }^{10}$ & & 0.88 & & 0.98 \\
\hline \multicolumn{5}{|l|}{ SLIC } \\
\hline Stone et al. ${ }^{5}$ & & 0.79 & & 0.98 \\
\hline Vaccaro et al. ${ }^{12}$ & & 0.71 & & 0.83 \\
\hline Van Middendorp et al. ${ }^{18}$ & & 0.78 & & $\mathrm{~N} / \mathrm{A}$ \\
\hline \multicolumn{5}{|l|}{ Morphology of SLIC only } \\
\hline Van Middendrop et al. ${ }^{18}$ & 0.29 & & $\mathrm{~N} / \mathrm{A}^{\mathrm{a}}$ & \\
\hline \multicolumn{5}{|l|}{ AO Spine } \\
\hline Vaccaro et al. ${ }^{12}$ & 0.64 & & 0.74 & \\
\hline
\end{tabular}

ICC, intraclass correlation coefficient; CSISS, Cervical Spine Injury Severity Score; SLIC, Subaxial Cervical Spine Injury Classification; AO, Arbeitsgemeinschaft für Osteosynthesefragen (German for "Association for the Study of Internal Fixation”); N/A, not applicable.

reliability of various authors on different classification systems for the subaxial cervical spine.

$\mathrm{AO}$ scale has been evaluated for the effect of timing of surgery in patients with subaxial cervical spinal trauma. A singlecenter prospective cohort study was conducted that included patients with traumatic CSCIs (C3-7), with 187 patients undergoing early decompression, and 215 patients delayed decompression surgery. Type A and F1-3 fractures are not required to undergo aggressive rapid decompression. The authors suggested that type $B$ and type $\mathrm{C} / \mathrm{F} 4$ fractures should receive early surgical treatment for better clinical outcomes. ${ }^{30}$

A web-based multicentre study was conducted where German and Dutch spine surgeons evaluated the computed tomography data of traumatic subaxial fractures. The fractures were classified using the AO spine classification. Next, 9 questions concerning the treatment algorithm were evaluated. Ten surgeons (5/country) evaluated 31 cases (310 votes). The fractures were classified as AO type A in 37\% (114 votes), type B in 50\% (155 votes), and type $C$ in $13 \%$ (41 votes). German spine surgeons had a lower threshold concerning the indication for surgical treatment (German, $94.2 \%$ vs. the Netherlands, $58.1 \%$; $\mathrm{p}<0.05$ ). German surgeons had a low threshold for surgery compared to Dutch surgeons (for type A2 and A3). Both agreed that 
type B and C fractures should be treated surgically. ${ }^{31}$

The AO Spine Classification Group was established to propose a revised AO Spine injury classification system. In a structured, iterative process involving 5 experienced spine trauma surgeons from various parts of the world, spinal injuries were classified independently by members of the classification group and analyzed for classification reliability. The reliability of injury types $(\mathrm{A}, \mathrm{B}, \mathrm{C})$ was good. Interobserver and intraobserver reliability, including subtypes, was substantial $\mathrm{k}=0.64$ and 0.75 , respectively. The lowest value for F1, F4, B2, and A3 and highest value for $\mathrm{A} 2, \mathrm{~A} 0, \mathrm{~A} 1$, and $\mathrm{B} 3 .^{32} \mathrm{AO}$ supplemental classification is promising, though it is not very user friendly and complicated for some (This was not voted and is not in WFNS Spine Committee guidelines).

\section{MANAGEMENT OF SUBAXIAL CERVICAL SPINE INJURIES}

\section{Materials and Methods}

Literature was searched from 2010 to 2020 on the surgical management of subaxial cervical spine injuries and the rationale of classification systems in helping to guide the treatment of subaxial cervical spine injury. "Management of subaxial cervical spine injuries" and the role of "SLICS" and "AO Spine" in management were the terms used to search the online literature. Google scholar database resulted in 5,510 hits. The search terms were further refined with the exclusion of non-English articles and articles on the axial cervical spine and thoracolumbar spine to identify a total of 210 relevant articles. Literature search on the PubMed database with the keywords mentioned above resulted in 148 hits, on the exclusion of non-English articles and the animal studies, 78 studies were selected (Fig. 4).

\section{Results}

Sixteen articles were found to be specific to the management of subaxial spine fractures, based on classification system and surgical approach to consider regarding various injury patterns. These articles were studied in detail. After discussion, the drafted statements were voted upon in Moscow in May 2019, followed by another voting in the Peshawar meeting of November 2019.

\section{Discussion}

The objectives for cervical spine injury management are to prevent neurological deficits, the return to maximum functional ability, with minimal residual pain, minimum of residual deformity, maintain stability, and cervical alignment, with preservation of mobility as much as possible. Within the literature, a high level of evidence on the surgical treatment of traumatic subaxial spine injuries is present in a few studies only. These studies did not conclude universally acknowledged treatment concepts for different types of subaxial cervical spine fractures., ${ }^{2,33-35}$ Surgical treatment enables not only the optimal reduction and direct decompression of the exiting nerve roots and the spinal cord but also the immediate fixation with minimum need of external fixation, allowing early mobilization of the patient and decreasing complications. Evidence is abundant in early surgery and its association with improved neurological outcomes in

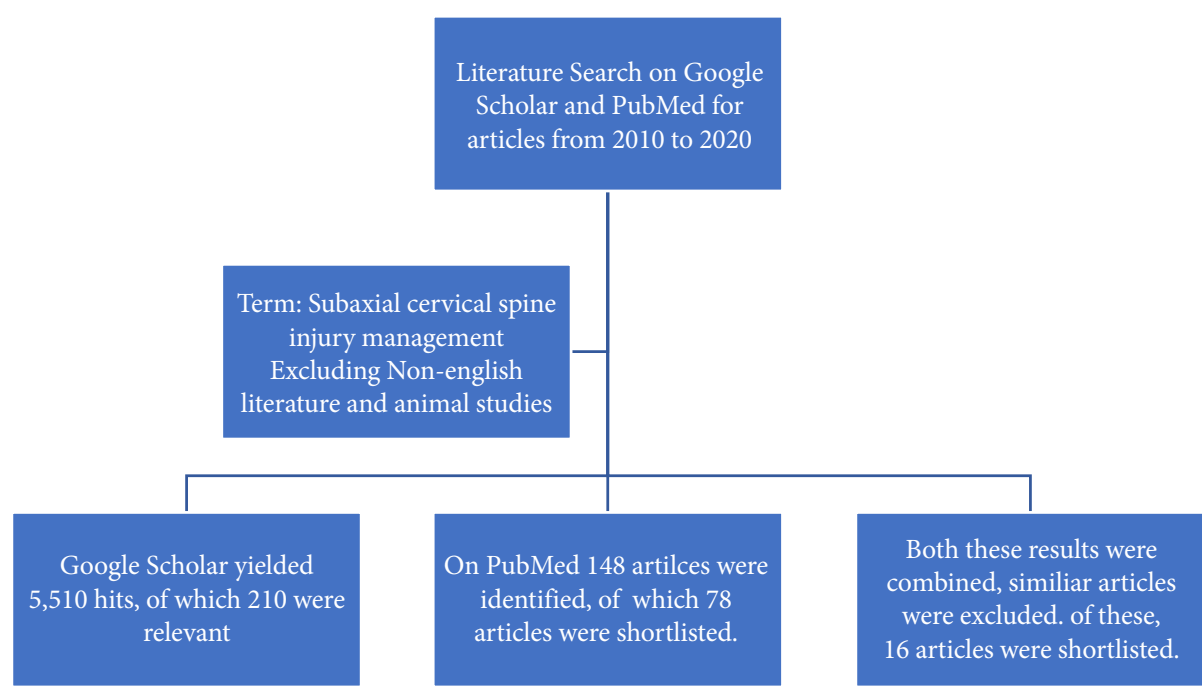

Fig. 4. Literature search for management protocols of subaxial cervical spine injury. 
subaxial cervical spine injuries. ${ }^{19,36-38}$ The initial emergency department management includes hemodynamic stabilization of the patient, which proceeds concomitantly with a clinical and radiological assessment of the patient. During this period, immobilization of the cervical spine is a priority. Decompression and stabilization should be performed as quickly as possible after appropriate patient resuscitation and hemodynamic stabilization. Early surgical intervention ( $<12-72$ hours) is safe and effective and does not increase the risk of morbidity or mortality of patients with cervical spinal cord injury. Early timing further resulted in improved neurologic outcome in cervical spine injuries. ${ }^{36,37}$

In this review, we discuss the management of subaxial cervical spine injuries, including various reduction methods used for these injuries, which patients need to undergo surgery and the role of neurology, instability, and deformity in guiding the conservative or surgical management. Indications of anterior versus posterior decompression have been reviewed, and the surgical approach depending on the morphology of the injury are described.

\section{Reduction of Fractures/Dislocations}

Closed or open reduction of subaxial cervical fractures or dislocations is recommended for urgent decompression of the spinal cord and restoration of the spinal canal. Stable immobilization by either internal fixation or external immobilization allows for early rehabilitation of patients. Treatment of subaxial cervical fractures and dislocations with prolonged bed rest in traction is undertaken only if more contemporary treatment options are not available. ${ }^{36}$ Performing a closed reduction before obtaining an MRI should only be considered in an awake patient who is neurologically intact and able to cooperate with the exam. Urgent closed reduction can also be considered in a patient who is awake and alert but presents with complete spinal cord injury, without knowing the status of the intervertebral disc given the assumption that further damage to neurological function is likely negligible. Immediate closed reduction by Gardner-Wells tongs can be undertaken if definitive surgical treatment is planned, or in case of nonsurgical therapy, the halo may be applied. The reduction is performed with the use of Gardner-Wells tongs and the sequential addition of weight to apply traction. ${ }^{19}$ Initially, $5-\mathrm{kg}$ weight is applied, followed by progressive addition of $2 \mathrm{~kg}$ every 10 minutes (until unlocking of facets or over distraction seen on $\mathrm{x}$-ray or worsening of neurological signs/symptoms). If unsuccessful, emergency open reduction is recommended to realign the spine and decompress the neural elements. ${ }^{39}$

\section{Indications for Surgery}

Various indications for surgery have been reported in the literature depending on the neurology, instability identified radiologically, and the presence of deformity. Neurologically, in cases of hyperextension injury with central cord syndrome, management may be conservative. Also, complete neurological deficit by itself does not constitute an indication for surgery, whereas progressive neurological deficit is a well-accepted indication. Controversy exists when surgery for a stable incomplete deficit with evidence of significant spinal canal compromise is undertaken. In these cases, reduction in local tissue pressure by realignment of the spine or by direct surgical decompression of the spinal cord may promote neurological recovery by improving circulation/oxygenation. Hence, Surgery is indicated for the presence of progressive neurological deficits with significant spinal canal compromise. Surgery may be indicated for the stable incomplete deficit with substantial spinal canal compromise. ${ }^{36,39}$

Instability is a primary indication for surgery, but to define what injury constitutes instability in the subaxial cervical spine is difficult. Various classification methods have been proposed for this purpose. Two-column (Holdsworth) theory, which formed the basis for Allen's classification and subaxial injury classification and the most widely accepted 3-column (Denis) classification, are examples. White and Punjabi scoring system assigns points on the competence of anterior and posterior spine elements, the extent of static and dynamic displacement, presence of neurologic injury, and anticipated physiologic loads. However, the SLICS system by Spine Trauma Study Group and the AO Spine Knowledge Forum group are the most widely recognized classification systems utilized to access if surgery is indicated. Based on deformity, surgery is indicated in cases of burst fractures where the deformity is present. Burst fractures due to axial compression could be stable because posterior ligaments are intact, and cervical orthosis may be recommended. Others may have significant kyphosis that merits surgery to limit adjacent segment degeneration and pain in the future. ${ }^{39}$

\section{Selection of Surgical Approach - Anterior vs. Posterior Approach for Subaxial Cervical Spine Injury}

Anterior or posterior stabilization may be chosen to treat cervical subaxial spine injuries surgically. The choice of anterior versus posterior approach should be based on the pathology of the injury pattern. Anterior approaches have the advantages of the supine position, easy accessibility, less blood loss, minimal surgical trauma, and infection. They can achieve direct anterior decompression of the neural elements, removing ventral com- 
pressive structures such as disk and bone. Anterior column injuries (burst vertebral body, retrolisthesis) may be managed with corpectomy with instrumented fusion. Anterior surgery may be contraindicated in case of significant posterior lesions compromising the spinal cord or roots. It is best avoided in cases of clinically relevant dural leaks or locked facet joints, which

Table 6. Subaxial cervical spine management on the basis of morphology

\begin{tabular}{|c|c|c|}
\hline Mechanism (Allen's stage) & Morphology and AO type & Management \\
\hline $\begin{array}{l}\text { Vertebral compression } \\
\text { stages } 1 \& 2\end{array}$ & $\begin{array}{l}\text { Superior or inferior endplate fracture AO Spine A1 } \\
\text { Both endplates AO Spine A2 (Fig. 5) }\end{array}$ & Stable, external immobilization for $8-12$ weeks \\
\hline $\begin{array}{l}\text { Vertebral compression } \\
\text { stage } 3\end{array}$ & $\begin{array}{l}\text { Burst vertebral body with variable comminution } \\
\text { AO Spine A3 and A4 (Fig. 5) }\end{array}$ & $\begin{array}{l}\text { SOMI brace/halo } 12 \text { weeks with intact neurology } \\
\text { Surgery- worsening neurological deficit (anterior cervical } \\
\text { corpectomy and instrumented fusion, or posterior lateral } \\
\text { mass/pedicle screw stabilization) }\end{array}$ \\
\hline $\begin{array}{l}\text { Compressive flexion stages } \\
1 \& 2\end{array}$ & $\begin{array}{l}\text { Wedge (CF1) } \\
\text { Wedge with localized kyphosis or breaking (CF2) } \\
\text { AO Spine A1 (Fig. 6) }\end{array}$ & Cervical orthosis: 8-12 weeks \\
\hline $\begin{array}{l}\text { Compressive flexion stages } \\
3 \& 4\end{array}$ & $\begin{array}{l}\text { Teardrop CF3, retrolisthesis }<3 \text { mm CF4 } \\
\text { AO Spine type A (Fig. 6) }\end{array}$ & Anterior corpectomy with instrumented fusion \\
\hline Compression flexion stage 5 & $\begin{array}{l}\text { Retrolisthesis }>3 \mathrm{~mm} \\
\text { AO Spine type C (Fig. 6) }\end{array}$ & $\begin{array}{l}\text { Anterior corpectomy with instrumented fusion/posterior } \\
\text { stabilization in severe posterior ligament injury or when } \\
\text { multilevel anterior corpectomy }\end{array}$ \\
\hline Distraction flexion stage 1 & Flexion sprain & Rigid external immobilization for 8-12 weeks \\
\hline Distraction flexion stage 2 & Unifacet dislocation & Closed/posterior or anterior open reduction \\
\hline $\begin{array}{l}\text { Distraction flexion } \\
\text { stages } 3-5\end{array}$ & $\begin{array}{l}\text { Allen's } 3 \text { (Bifacet dislocation with anterolisthesis } \\
\quad<50 \% \text { ) } \\
\text { Allen's } 4 \text { (Anterolisthesis }>50 \% \text { ) } \\
\text { Allen's } 5 \text { Complete spondyloptosis } \\
\text { AO Spine type F4 (Fig. } 7 \text { ) }\end{array}$ & $\begin{array}{l}\text { Anterior or posterior open reduction (for osteoporosis, } \\
\text { posterior reduction) }\end{array}$ \\
\hline $\begin{array}{l}\text { Compressive extension } \\
\text { stages } 1 \& 2\end{array}$ & $\begin{array}{l}\text { Unilateral vertebral arch fracture, bilateral } \\
\text { vertebral arch fractures } \\
\text { AO Spine A0 (Fig. 8) }\end{array}$ & Rigid cervical orthosis for 12 weeks \\
\hline $\begin{array}{l}\text { Compressive extension } \\
\text { stage } 3\end{array}$ & $\begin{array}{l}\text { Bilateral vertebral arch fractures with the anterior } \\
\text { extension of the fracture, with maintained spinal } \\
\text { alignment } \\
\text { AO Spine B3 (Fig. 8) }\end{array}$ & External immobilization \\
\hline $\begin{array}{l}\text { Compressive extension } \\
\text { stages } 4 \text { \& } 5\end{array}$ & $\begin{array}{l}\text { Dissociation between anterior and posterior } \\
\text { vertebral columns with progressive anterior } \\
\text { translation AO Spine type C (Fig. } 8 \text { ) }\end{array}$ & $\begin{array}{l}\text { Surgery with multilevel posterior lateral mass or pedicle } \\
\text { screw fixation } \\
\text { With significant vertebral body comminution, additional } \\
\text { anterior reconstruction may be required to restore the } \\
\text { load-bearing mechanics }\end{array}$ \\
\hline Distractive extension stage 1 & $\begin{array}{l}\text { Distraction injury of the anterior column but PLL } \\
\text { intact } \\
\text { AO Spine type B3 (Fig. 11) }\end{array}$ & $\begin{array}{l}\text { Surgically managed with anterior cervical fusion with } \\
\text { plating }\end{array}$ \\
\hline Distractive extension stage 2 & $\begin{array}{l}\text { Distraction injury involving both columns with } \\
\text { PLL torn } \\
\text { AO Spine type C (Fig. 11) }\end{array}$ & $\begin{array}{l}\text { Posterior reduction with stabilization+anterior fusion if } \\
\text { anterior column involved } \\
\text { If the spine gets realigned with gentle traction, then } \\
\text { multilevel posterior instrumentation } \\
\text { If spinal realignment cannot be achieved, then posterior } \\
\text { instrumentation+anterior decompression and fusion }\end{array}$ \\
\hline Lateral flexion stage 1 & Ipsilateral posterior elements involved & Managed nonsurgically \\
\hline Lateral flexion stage 2 & Contralateral posterior elements involved & Posterior stabilization for one motion segment \\
\hline
\end{tabular}

AO, Arbeitsgemeinschaft für Osteosynthesefragen (German for "Association for the Study of Internal Fixation”); SOMI Brace, sternal occipital mandibular immobilizer. 
are nonreducible by traction or even anterior open surgery.,36

In select posterior injuries, the anterior approach may still be used. Anterior cervical discectomy and fusion performed using interbody structural allograft and plate fixation are highly effective in various cases. The treatment of unstable posterior cervical lateral mass, facet, and ligamentous injuries may be managed with this approach. Radiographic outcomes concerning segmental stability are excellent, and fusion rates with the use of grafts and plating are high. Results for pain, function, and patient satisfaction are high, and the complication rate is low. ${ }^{40}$

Anterior approaches may be associated with fewer wound complications and a higher fusion rate at a small risk of postoperative swallowing difficulties. ${ }^{22}$ Furthermore, highly unstable injuries may need a combined anteroposterior surgery or if an anterior stabilization may appear insufficient intraoperatively.

Posterior approaches, based on rigid fixation techniques with lateral mass or pedicle screws, are a good alternative for distraction and translation/rotational injuries, as reduction forces can be directly applied to realign the spine. Proponents of posterior fixation and fusion as a treatment for subaxial cervical spinal fracture injuries cite superior biomechanics as the primary advantage of this internal fixation strategy. Furthermore, open reduction of facet dislocations is straightforward with the posterior approach. ${ }^{41}$

There are, however, no differences in neurological recovery or patient-reported outcome measures with anterior versus posterior approaches. Both are viable options for decompression and fusion and should be tailored according to fracture morphology and patient-specific factors. ${ }^{22}$

\section{Surgical Approach According to the Morphology of Injury}

The principal aims of surgery are to realign the spine, decompress the neural elements, and provide mechanical stability. This can be achieved by an anterior decompression (discectomy/corpectomy) and instrumented fusion, a posterior stabilization with or without decompression, and a combination of the 2 approaches.

The decision regarding approach selection is based primarily on the morphology of the injury (Table 6 and Figs. 5-8). ${ }^{39}$ Ver-
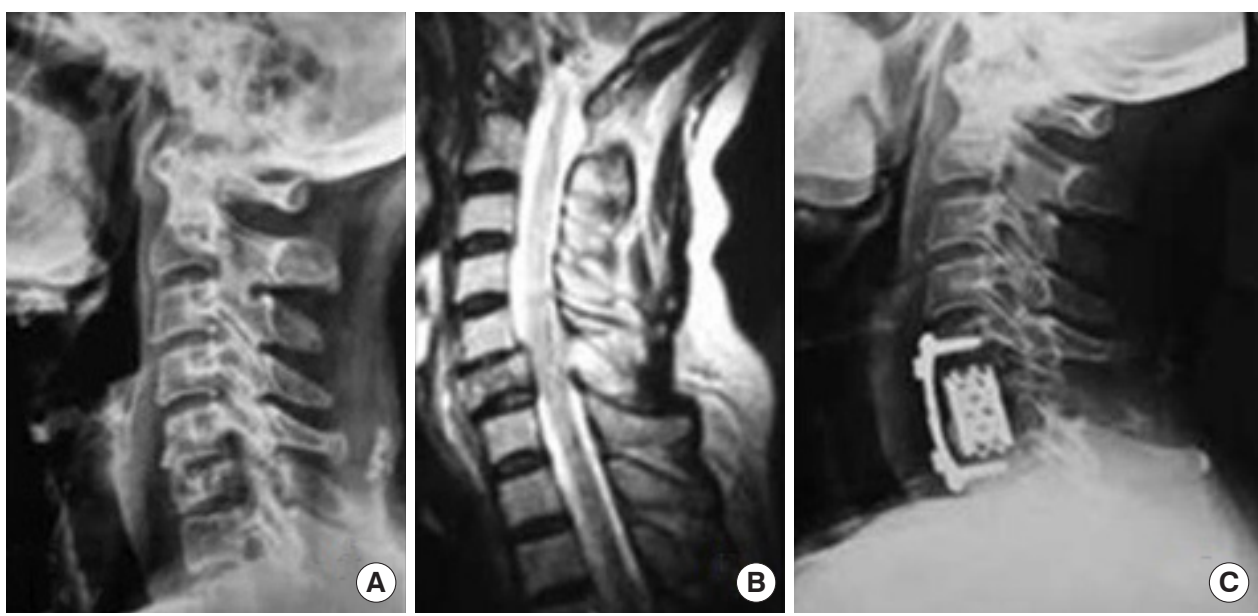

Fig. 5. (A) X-ray cervical spine lateral view showing vertical compression fracture stage 3. (B) Sagittal T2-weighted magnetic resonance imaging cervical spine showing vertical compression. (C) X-ray cervical spine lateral view showing surgical management of vertical compression stage 3 injury. Reprinted from Zaveri and Das. Indian J Orthop 2017;51:633. ${ }^{39}$

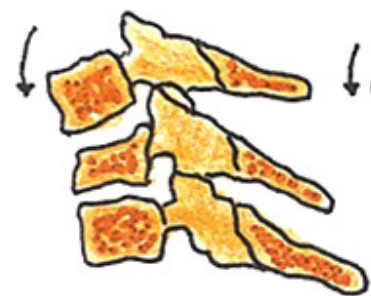

Stage I

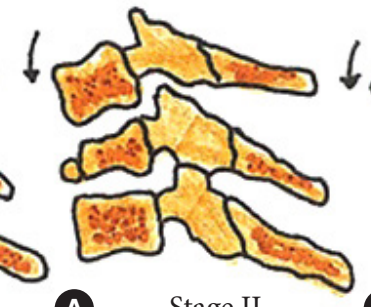

A Stage II

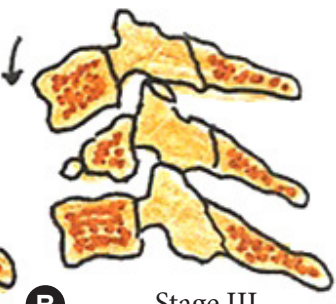

B Stage III

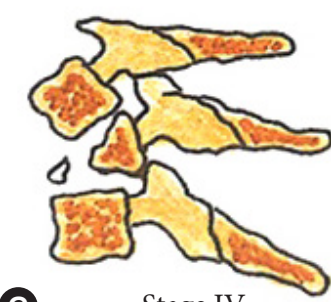

Stage IV

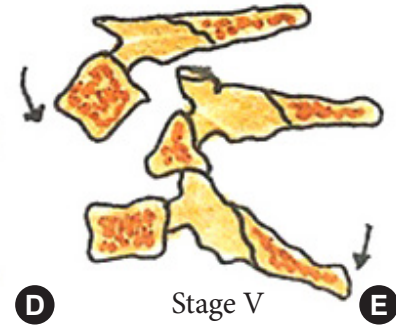

Fig. 6. Stages of a compressive flexion injury wedge compression (A), anteroinferior beaking (B), teardrop fracture (C), retrolisthesis of the posterosuperior fragment by $<3 \mathrm{~mm}(\mathrm{D})$, retrolisthesis $>3 \mathrm{~mm}(\mathrm{E})$. 
tebral compression fractures may involve the endplates only, with wedge compression or present as burst fractures (AO Spine types A3 and A4). Vertebral compression fractures with intact neurology may be managed with external immobilization or surgery. However, Koivikko et al. ${ }^{42}$ reported better sagittal alignment, fusion rates, and neurological outcomes following surgery compared to halo-vest immobilization for 69 patients with a teardrop and burst fractures. Complications of halo use are also moderately high, including the loosening of infected pins, neck pain, or decreased range of motion. Complication rates in geriatric patients averaged 33\% (Fig. 5). ${ }^{43}$

Distraction flexion injuries are the most common injury pattern seen in the subaxial cervical spine and commonly occurs in young males. Facet injuries are typically the result of a flexion and distraction injury and may contain an element of rotation. These injuries can be purely ligamentous or have substantial bony involvement of the facet and lateral mass. They run the spectrum from fracture and subluxation to a locked dislocation. In the event of failed closed reduction, an open reduction can be performed by both anterior and posterior approaches. In the case of unilateral facet injuries, fractures involving $\geq 40 \%$ of the absolute height of the intact lateral mass or an absolute height of $1 \mathrm{~cm}$ (AO Spine type F2) were at increased risk for failure of nonoperative treatment. For these fractures, single-level anterior interbody fusion is recommended. ${ }^{1,36}$ In more complex fracture-dislocations, a combined anterior and posterior approach is required. This approach provides adequate discectomy, reduction, and anterior column reconstruction with grafting. Also, the reconstitution of the posterior tension band with stabilization and fusion can be carried out (Table 6, Fig. 7). ${ }^{35}$ Figs. 9 and 10 depict the algorithm for stepwise management of subaxial cervical spine injuries.

\section{MANAGEMENT OF TRAUMATIC LOCKED FACETS}

\section{Materials and Methods}

A literature search was done using a keyword' management of traumatic facet locks' in PubMed for 10 years between 2010 to 2020. Many articles were similar; few relevant papers were found to be useful for submission for recommendations were selected.

\section{Results}

The literature search yielded various articles of which 13 articles were selected to be reviewed in detail. These articles formed
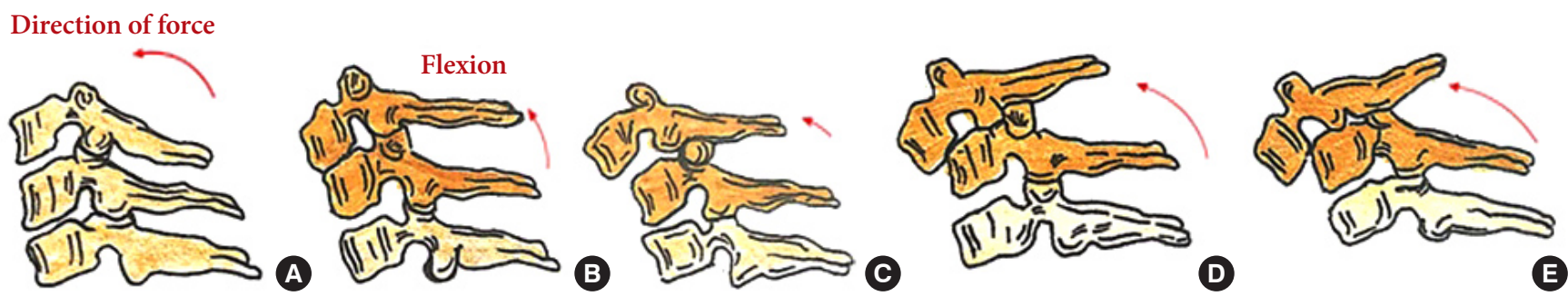

Fig. 7. Stages of distractive flexion injury: flexion sprain (A), unifacet dislocation (B), bifacet dislocation with antero-listhesis $<50 \%$ (C), anterolisthesis $>50 \%$ (D), complete spondyloptosis (E).

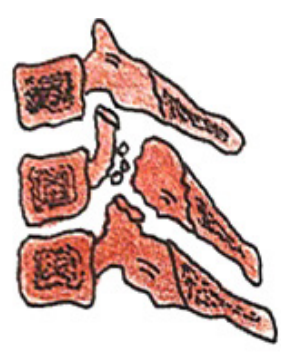

Stage I

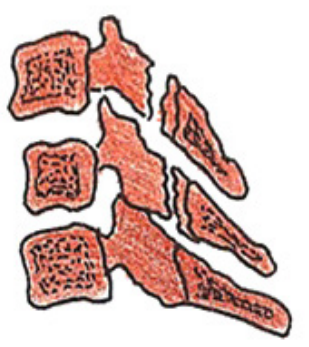

A

Stage II

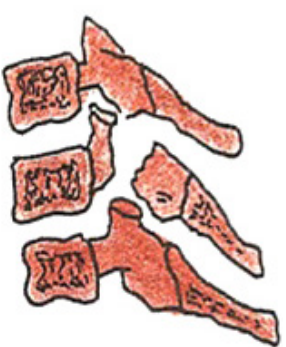

B Stage III

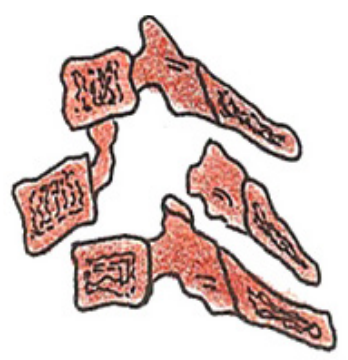

C

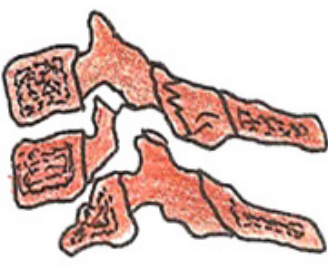

D

Fig. 8. Stages of a compressive extension injury: unilateral vertebral arch fracture (A), bilateral vertebral arch fractures (B), bilateral vertebral arch fractures with the anterior extension of the fracture $(C)$, but spinal alignment maintained, dissociation between anterior and posterior vertebral columns with progressive anterior translation (D, E). 


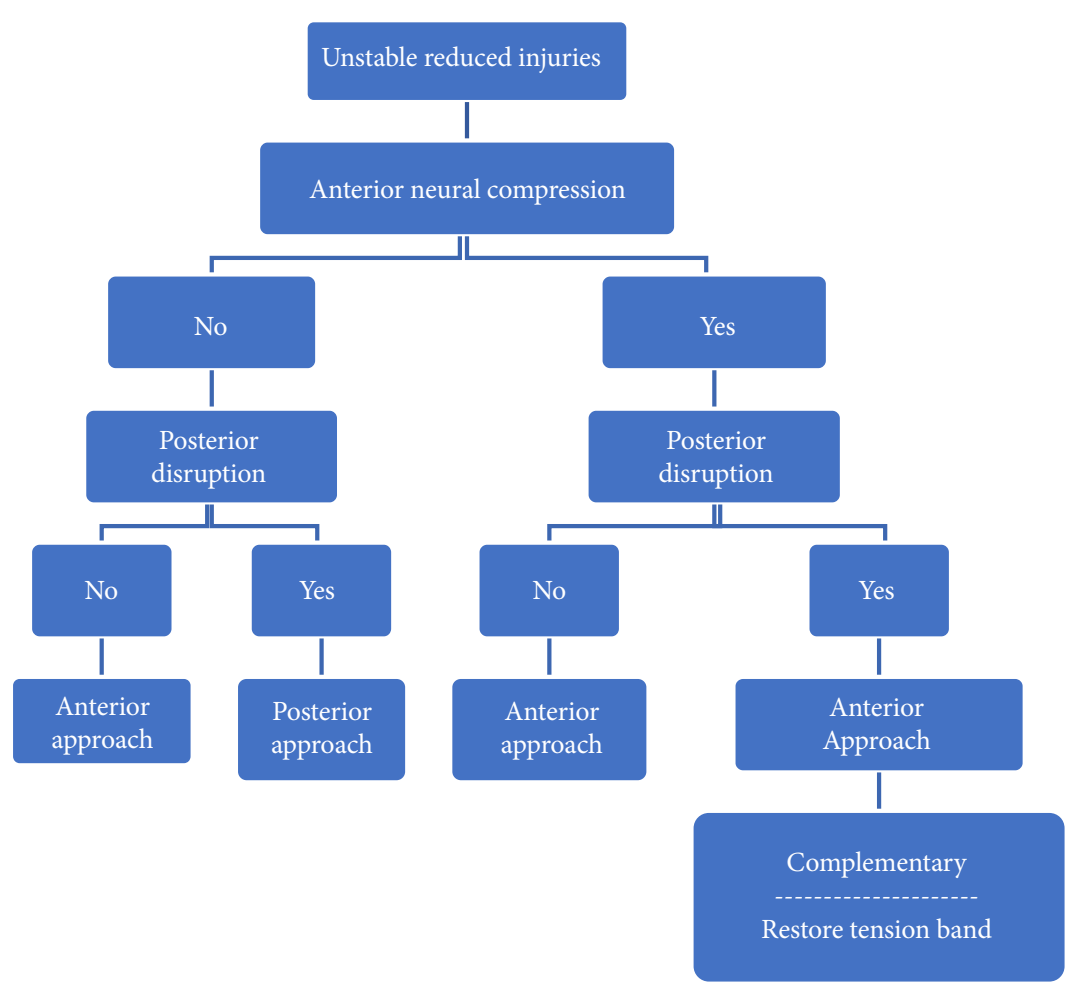

Fig. 9. Algorithm for management of unstable reduced fractures of subaxial spine.

the basis for WFNS Spine Committee Recommendations regarding management of traumatic locked facets. The following subjects were studied: closed reduction, cervical traction, approaches and techniques, and algorithms.

\section{Discussion}

Management of the posttraumatic locked facet joint is a fascinating subject. Facet locks are more often seen at the subaxial cervical spine. They are due to a combination of movement at a joint when rotation with flexion and extension is involved in trauma. Management is more challenging and interesting when no neurological deficit was found. A literature search was done on these subjects, and relevant articles in the last decade were analyzed. Though different surgeons used various methods, some of the most common grounds in techniques and approaches were identified. While most of the facet lock (dislocations) can be managed through an anterior approach, few needed posterior approaches and rarely a combined approach $\left(360^{\circ}\right)$. MRI in present-day is suggested to help in the decision making, while traction and closed reduction is performed cautiously.

\section{Closed Reduction Techniques}

Closed reduction techniques are less frequently performed.
Closed reduction using the Halo traction device has shown good results, especially in lower cervical spine locked facets. Reinhold et al., ${ }^{44}$ in their 117 patients' study, concluded that if closed reductions are performed within 4 hours of injury, the reduction achievement and neurological improvement are better. Wang et al., ${ }^{45}$ in their retrospective analysis of 12 patients, reported no worsening while using manual counter-rotation technique. Early traction with Gardner and Wells tongs has achieved a reduction in $97 \%$ of patients analyzed retrospectively by Grant et al. ${ }^{46}$ Two patients (2.4\%) failed to reduce, and 1 (1.3\%) deteriorated in their analysis of 121 patients. They concluded that the chance of deterioration is rare. They felt that closed reduction should be attempted only by experienced spinal surgeons. ${ }^{47}$

\section{Traction}

Craniocervical traction has been a mainstay in the management of cervical spine injury for long, and in particular, its application in unlocking the jumped facets. Closed reduction using skull tongs can cause decompression of the spinal cord and achieve a normal alignment of the spine. There are also some reports that if the reduction is achieved early enough, the neurological improvement will be more. ${ }^{48}$ Historically, there were concerns about neurologic deficit following traction to the up 


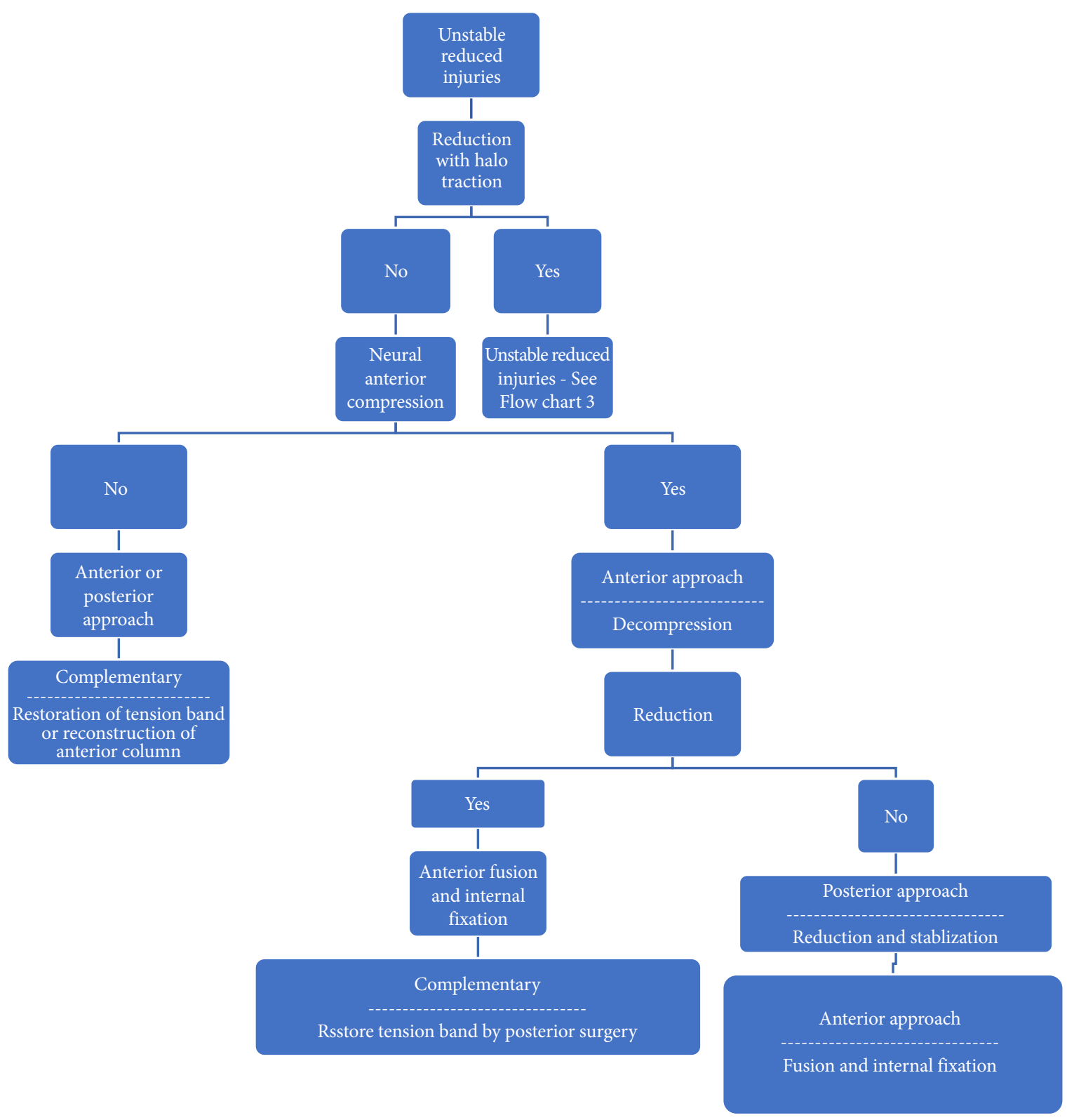

Fig. 10. Algorithm for management of displaced unstable fractures of subaxial spine.

to $1.84 \%$ to $10 \%$, attributed to halo, traction, spinal cord distraction, and disc protrusion. ${ }^{49}$

Closed reduction should be performed as early as possible. It is not always possible, as it needs close monitoring and fluoroscopy. Closed reduction should ideally be performed under fluoroscopy by a proficient surgeon. It is not advisable in confused patients who cannot communicate. ${ }^{48}$

In most cases, closed reduction is performed just before the surgery. Gattozzi et al. ${ }^{50}$ recommended early surgical intervention without traction in acute settings with the application of traction after anesthesia. Most spine surgeons prefer urgent an- terior decompression in acute cases. Rarely, a posterior open reduction is performed if an anterior open reduction is not attained. The essential need for preoperative MRI was questioned by Vaccaro et al. ${ }^{51}$ when they reported 9 patients who had dislocated cervical facets. They underwent pre-reduction MRI, and 2 of the 9 had disk herniation identified on the MRI. A closed reduction was then performed on all patients, without worsening of their neurologic grade. Five patients had a herniated disk after a closed reduction on postreduction MRI. Based on these results, the authors stated that it was likely safe to perform a closed reduction in an awake, alert, and cooperative patient. 


\section{Approaches and Techniques}

While the majority of facet locks can be managed by an ante-
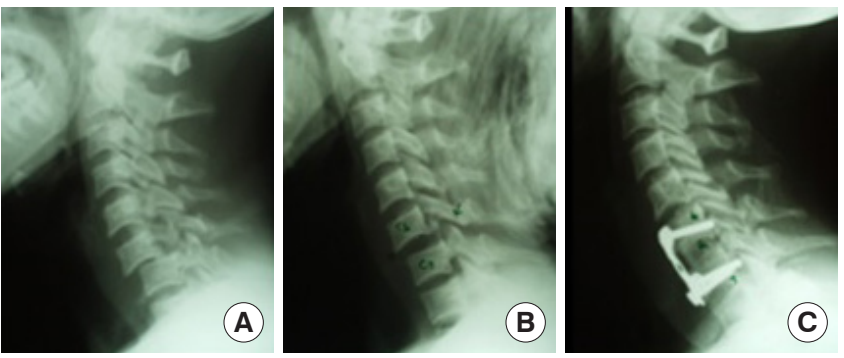

Fig. 11. Anterior approach (facet lock reduction and anterior fixation). (A) C6/7 facet dislocation (lock). (B) Traction reduction. (C) Anterior stabilization with interbody autograft. rior approach (Fig. 11A-C), those locked facets that could not be reduced by traction and after an anterior approach may need an additional posterior approach to directly de lock the diseased facets (Fig. 12A-F). ${ }^{38,52}$

Removal of disc material and release of ligaments during anterior surgery promotes the reduction of locked facets with sustained traction and muscle relaxants. Caspar pins placed over vertebral bodies can be used to distract the facets, and posterior compression of the rostral body can reduce the facet lock finally. ${ }^{53}$ Similarly, Cobbs elevator can be used in the intervertebral space to achieve reduction. Li et al. ${ }^{54}$ have described anterior cervical distraction and screw elevating - pulling reduction technique using anterior plates with good results. In the posterior
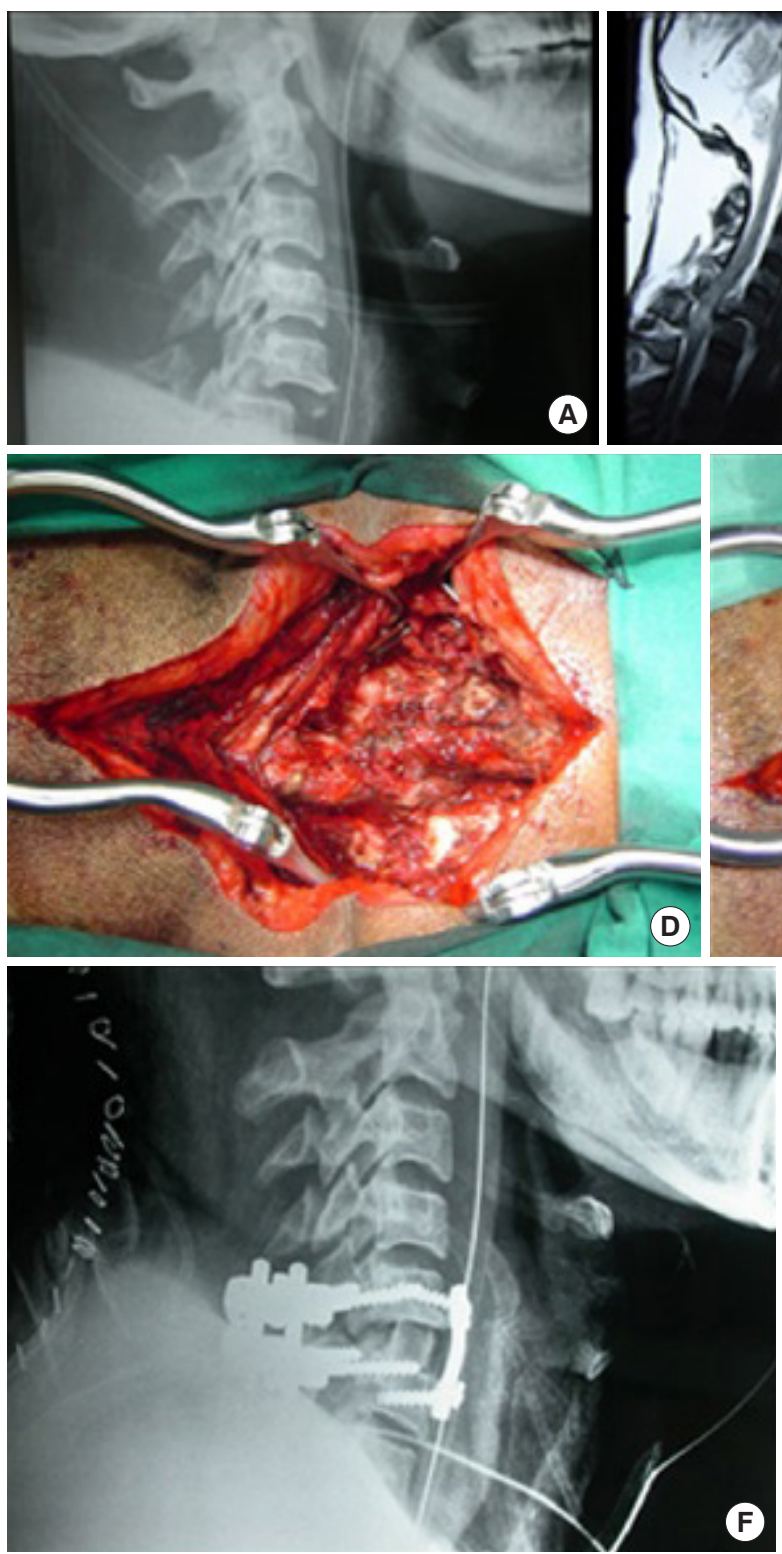
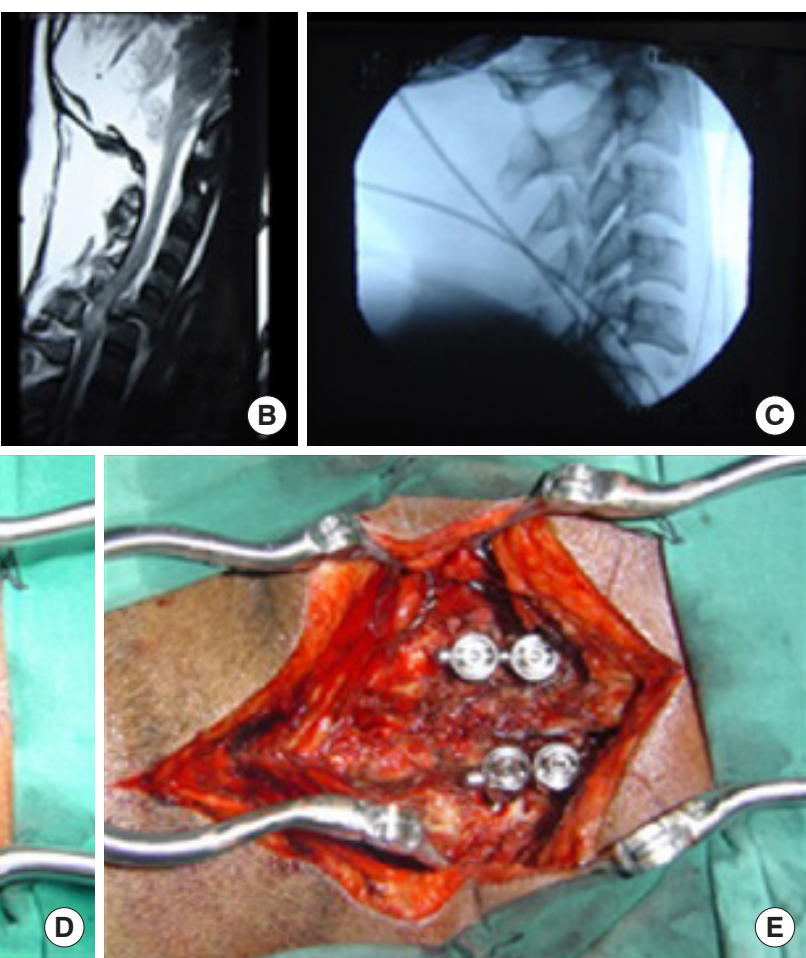

Fig. 12. Irreducible locked facet management by combined approach. (A) C5/6 facet lock. (B) Magnetic resonance imaging showing large disc prolapse. (C) Irreductible after dissectomy through anterior approach. (D) Patient rotated and locked facet exposed. (E) Upper half of jumped facet drilled out, reduction achieved and posterior stabilization done. (F) After posterior reduction patient again rotated and anterior stabilization done along with autograft. 
approach, a direct reduction of a locked facet can be achieved by drilling out the upper half of jumped facet and yanking the lower fact with a curette. ${ }^{55}$

\section{Algorithms}

Of all the algorithms, Stellerman's is the simplest and easy to follow. ${ }^{56}$ Few modifications of the Stellerman's are reported, but they are not practical in all institutions. Literature is not clear about the management of delayed or neglected locked facets. ${ }^{56}$

\section{Radiology}

Though x-rays (lateral views) and CT scan with 3-dimensional reconstruction are regular and mandatory, MRI of the cervical spine may be performed to assess the soft tissues like ligaments and disc material and to predict prognosis. Large disc material in the canal in a locked facet demands an anterior approach. However, to choose a posterior approach, it is advised to do MRI cervical spine to rule out prolapsed and migrated disc material in the anterior canal.

\section{VERTEBRAL ARTERY INJURIES AFTER CERVICAL TRAUMA}

\section{Materials and Methods}

A PubMed search with the keywords "vertebral artery injury and cervical fracture" exhibited 2,328 references from the last 15 years.

The questions to be answered were:

1. What are the appropriate diagnostic tests for identifying VAI?

2. What is the optimal treatment for VAI (observation compared to anticoagulation with heparin or to aspirin therapy)?

3. What is the role of endovascular treatment for VAI?

Based on the most relevant literature, 4 statements were issued for voting at Moscow in May 2019, and later, voting was conducted at Peshawar in November 2019. The consensus was reached at all the statements.

\section{Results}

The major difficulty regarding the data analysis in the published series relates to the heterogynous enrollment of patients with different screening and diagnostic criteria applied to the substantial variability in the incidence of each grade of VAI. This results in the unclear natural history of the morbidity and a wide range of reported stroke and death rates after VAI.

Most studies extracted from the literature search were the case reports, small case series, editorials, letters to the editor, and re- view articles that were eliminated. Only one class I study, comparing digital angiography and computerized angiography (CTA) as a diagnostic tool, was found. Twenty-five studies with the class III medical evidence case series were shortlisted and studied in detail.

\section{Discussion}

The incidence of VAI is around $0.5 \%$ of all trauma patients, and $70 \%$ of VAI in blunt trauma have associated cervical fractures. Although related to vertebrobasilar insufficiency, there are neither pathognomonic symptoms nor signs of VAI. Furthermore, VAI shows a variable time presentation after the initial injury.

VAI occurred in $17 \%$ (42 of 253) of patients screened by CTA with neurological events occurring in 14\% (6 of 42), and a strokerelated mortality rate of $4.8 \%$ ( 2 of 42 ). ${ }^{3}$

It seems that VAI of any injury grade has a rather limited potential to cause ischemia or stroke. Despite the fact anticoagulation or antiplatelet therapy can reduce the risk of stroke, traumatic VAI is more likely to present in association with the most severe cervical spine and spinal cord injuries-all of which represent relative contraindications to anticoagulation and antiplatelet therapies.

\section{Appropriate Diagnostic Tests for VAI}

Angiography has been considered the gold standard to diagnose and grade VAI following cervical trauma. However, it is a time consuming and high logistic diagnostic tool with morbidity and mortality around $2 \%-3 \%$. Furthermore, the grading system, as assumed by Fassett et al., ${ }^{57}$ is not related to stroke incidence and neurological outcome.

On cervical spine $\mathrm{x}$-rays, certain types of fractures patterns may raise suspicion for VAI, but with very low sensitivity. Over the last decade, computerized CTA, using multislice machines, allowed for the identification of the local of the injury with a sensitivity report at $100 \%$. As proposed by Biffl et al., ${ }^{58}$ the clinical indications raising the suspicion of VAI are unexplained central or lateralizing neurological deficits, evidence of acute cerebral infarct on cranial CT scan, Glascow Coma Scale $<9$, diffuse axonal injury, skull base fracture, significant thoracic injury or first rib fracture. They detected a $2.4 \%$ incidence of VAI among those who met screening criteria and showed unequivocally that no patients with normal CTA developed symptoms/signs of missed injury, concluding that CTA is a reliable noninvasive screening test for clinically significant blunt cerebrovascular injuries (Fig. 13). ${ }^{59}$ 
Table 7. Grading of vertebral artery injury bases on angiographic appearance

\begin{tabular}{ll}
\hline Grade & \multicolumn{1}{c}{ Features } \\
\hline I & Dissection hematoma with $<25 \%$ lumen stenosis \\
II & Intravascular thrombus or dissection with $>25 \%$ lumen \\
& narrowing \\
III & Pseudoaneurysm \\
IV & Vessel occlusion \\
V & Vessel transection or major arteriovenous fistula
\end{tabular}
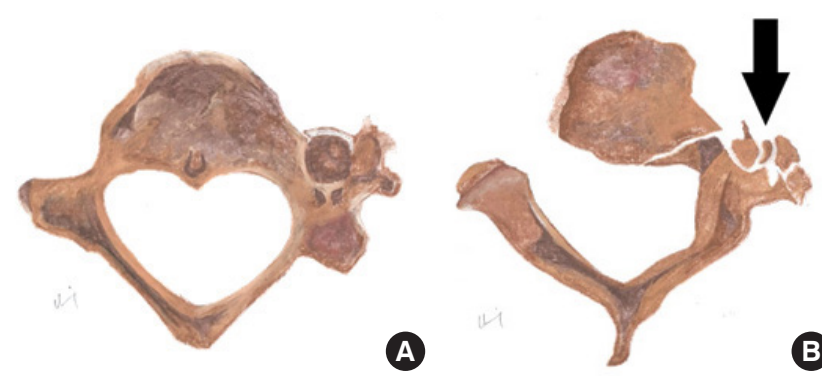

Fig. 13. Diagrammatic representation of normal transverse foramen (A) in comparison to vertebral artery injury (B) secondary to displaced fracture $>1 \mathrm{~mm}$ into the left transverse foramen in axial view. Black arrow indicates the fracture fragments with disruption of the left transverse foramen.

Eastman et al..$^{60}$ in 2006 conducted a prospective study comparing CTA to catheter angiography as a screening tool for vascular injuries within the neck with 146 trauma patients who met the Modified Denver Screening Criteria. They established that sensitivity, specificity, positive and negative predictive value, and accuracy of CTA for blunt cervical vascular injury (BCVI) were $97.7 \%, 100 \%, 100 \%, 99.3 \%$, and almost $100 \%$, respectively. This study provides Class I medical evidence on the utility of CTA to diagnose vascular injuries. It sets CTA as the new gold standard reference test for VAI in patients who have sustained blunt trauma.

Additionally, it has been published that Eco-Doppler and MRI angiography had a $28.5 \%$ and $20 \%$ sensitivity, respectively, and $100 \%$ specificity both of them. ${ }^{61}$ Friedman et al. ${ }^{62}$ prospectively evaluated, using an MRA, 37 patients admitted with "major" blunt cervical spine injury and compared these patients with a size-matched control group of patients without a history of cervical trauma. They found that $9 / 37$ patients had VAI, providing class III medical evidence.

\section{Screening High-Risk Patients}

When it comes to cervical fractures, to be cost-effective, CTA
Table 8. Clinical and imaging features of vertebral artery injury

\begin{tabular}{lcccc}
\hline Variable & $\begin{array}{c}\text { Sensiti- } \\
\text { vity } \%\end{array}$ & $\begin{array}{c}\text { Specifi- } \\
\text { city \% }\end{array}$ & PPV \% & NPV \% \\
\hline Transverse foramen fracture & 58 & 36 & 44 & 50 \\
Facet dislocation & 42 & 57 & 45 & 53 \\
Cervical subluxation & 56 & 71 & 38 & 83 \\
Complete spinal cord injury & 67 & 79 & 50 & 88 \\
\hline
\end{tabular}

PPV, positive predictive value; NPV, negative predictive value.

cannot be performed in all trauma patients as the low incidence and relatively benign natural history raises the utility of screening in asymptomatic patients (Table 7).

In 2013, Lebl et al., ${ }^{63}$ in a study using multidetector CTA to screen 1,204 patients, detected 253 patients (21\%) with VAI. VAI was diagnosed in $17 \%$, unilateral in $15 \%$, and bilateral in $1.6 \%$. VAI was associated with ankylosing spondylitis/diffuse idiopathic skeletal hyperostosis (crude odds ratio [OR], 8.04; 95\% confidence interval [CI]; $\mathrm{p}=0.034$ ), and occipitocervical dissociation $(\mathrm{p}<0.001)$ by univariate analysis and fracture displacement into the transverse foramen $1 \mathrm{~mm}$ or more (adjusted OR, 3.29; 95\% CI, 1.15-9.41; $\mathrm{p}=0.026$ ) by multivariate regression model. Neurological events were associated with male sex $(\mathrm{p}=0.024)$, facet subluxation/dislocation (crude OR, 9.00; 95\% CI; $p=0.004$ ) and the diagnosis of ankylosing spondylitis/diffuse idiopathic skeletal hyperostosis (OR, 40.67; 95\% CI; $\mathrm{p}<0.001$ ). They concluded that VAI associated with blunt cervical spine injury is a marker for more severely injured patients. ${ }^{63}$ The accuracy of various clinical and imaging features of the vertebral artery has been described in Table 8 .

\section{Treatment}

Most of the published series include mixed carotid and vertebral injury cases, as reported by Miller et al. ${ }^{64}$ in 2001 . However, these papers are different in injury mechanism, management, and prognosis. Many of the strokes attributable to VAI occur at the time of injury, typically before treatment and, thus, included in the "no treatment group" ${ }^{65}$ Consequently, the "treatment group" harbors a population not loaded with early stroke or death. This fuzzy logic and inappropriate assignment strategy limit the ability to identify a consistent or scientifically valid treatment strategy for VAI (lower class of evidence).

In 2009, Berne and Norwood ${ }^{66}$ identified 44 patients with VAI by CTA out of 8,292 admissions, patients who were treated with anticoagulants, aspirin, dual antiplatelet, endovascular, or subject to no treatment. The authors concluded that aggressive screening and individualized treatment failed to prevent VAI 
stroke and death (class III medical evidence).

In a retrospective review of a prospective database comparing anticoagulation and antiplatelet agents, a total of 282 asymptomatic patients underwent treatment for BCVI. The treatment options administered were; Heparin (192), aspirin (67), aspirin/ clopidogrel (23), or no treatment (107 patients). Cothren et al. ${ }^{67}$ found that the stroke rate in the treated group was $0.5 \%$, and in the "no treatment" group was $21.5 \%$. However, serious bleeding complications occurred in 8 patients treated with heparin, adding to the body of evidence that heparin therapy after BCVI has a higher risk than that associated with antiplatelet therapy in the treatment of BCVI. This study provides class II medical evidence in favor of treatment for BCVIs, but follow-up of patients beyond discharge was "limited," and patients found to have a stroke in the "no treatment" group.

Contraindications to anticoagulation or antiplatelet therapy for VAI may reach $40 \%(n=250)$ of patients. Contraindications are intracranial hemorrhage $30 \%$, intra-abdominal or intrathoracic injury $11 \%$, spinal surgery $22 \%$, other $5 \%$. VAI complications may occur days to years following the injury, demanding a close clinical and radiological follow-up.

Most of the endovascular management revised papers were case reports with either a few numbers of patients enrolled or no prospective randomized design, hampering to extract valid conclusions.

\section{CONCLUSION}

The WFNS guidelines for subaxial cervical spine trauma are of immense importance in shifting the management of subaxial spine injuries from anecdotal practice to a comparatively systematic evidence-based approach. There is a lack of class 1 evidence studies on classification, management, locked facet and vertebral artery injuries of subaxial spine. The consensus established guidelines on the classification and management of subaxial cervical spine injuries, with specific management protocols for injuries associated with locked facets and vertebral artery injuries. It is high time that properly designed randomized controlled trials should be undertaken, to improve the management protocols of subaxial cervical spine injuries.

\section{WFNS Consensus - Subaxial Cervical Spine Injury Classification System}

- Subaxial Injury Classification (SLIC) system is safe and effective in guiding the treatment of subaxial cervical spine injury. There is a good agreement rate (>90\%) in the SLIC score (morphology, neurology, and DLC) and the treatment chosen. (100\% consensus)

- To achieve a more precise classification of subaxial fractures, we suggest the use of MRI as well. (100\% consensus)

- SLICS is easy for surgeons and residents to reproduce with relatively better interobserver reliability. ( $100 \%$ consensus)

- SLICS should be used as the standard of care to guide further treatment and given preference over other present classification. (100\% consensus)

- For injuries with a SLIC score of less than 3, nonsurgical treatment with a rigid collar for 6 to 12 weeks is recommended. (100\% consensus)

\section{WFNS Consensus - Management of Subaxial Cervical Spine Injuries}

- For injuries with a SLIC score of more than 4, early surgery is recommended. ( $100 \%$ consensus)

- Surgery is indicated for the presence of progressive neurological deficit or stable incomplete deficit with significant spinal canal compromise. (100\% consensus)

- Anterior surgeries are recommended for significant anterior column injuries. ( $92 \%$ consensus)

- Additional posterior surgeries should be considered for patients who require multilevel corpectomy, and for patients with severe dissociation (complex) injuries. (100\% consensus)

- Although posterior surgeries are suggested for patients with osteoporosis and ankylosing spondylitis, there is no consensus on that. ( $23 \%$ consensus)

- In the management of locked facets, if a posterior approach is considered, preoperative MRI is recommended. (100\% Consensus)

\section{WFNS Consensus - Management of Traumatic Locked Facets}

- Traction help in immobilizing the unstable segment and may help reduce. (100\% consensus)

- In the majority of acute ( $\leq 3$ days) locked facets, anterior surgical techniques are sufficient to manage successfully. ( $82 \%$ consensus)

- In chronic locked facet ( $>2$ weeks), lower cervical locked facets with no/insignificant disc prolapse, and in conditions where the anterior approach is not feasible, a posterior approach is indicated. (100\% consensus)

- All locked facets should be reduced in an emergency, and surgery should be performed as soon as possible $100 \%$. 
(100\% consensus)

\section{WFNS Consensus - Vertebral Artery Injuries After Cervical Trauma}

- CTA is recommended, as a screening tool, in selected patients after blunt cervical trauma with a fracture near the vertebral artery course (level I). (100\% consensus)

- If CTA is abnormal for VAI and endovascular therapy is a potential treatment, conventional catheter angiography is recommended (level III). (79\% consensus)

- For patients in which endovascular treatment for VAI is not suggested, the choice of therapy - anticoagulation therapy versus antiplatelet therapy versus no treatment-should be individualized based on the patient's VAI characteristic, the associated injuries, and the risk of bleeding (level III). (93\% consensus)

- The role of endovascular therapy in VAI has yet to be defined; therefore, no recommendation regarding its use in the treatment of VAI can be offered (level III). (92\% consensus)

\section{CONFLICT OF INTEREST}

The authors have nothing to disclose.

\section{REFERENCES}

1. Aebi M. Surgical treatment of upper, middle and lower cervical injuries and non-unions by anterior procedures. Eur Spine J 2010;19 Suppl 1(Suppl 1):S33-9.

2. Dvorak MF, Fisher CG, Fehlings MG, et al. The surgical approach to subaxial cervical spine injuries: an evidence-based algorithm based on the SLIC classification system. Spine (Phila Pa 1976) 2007;32:2620-9.

3. Lebl DR, Bono CM, Velmahos G, et al. Vertebral artery injury associated with blunt cervical spine trauma: a multivariate regression analysis. Spine (Phila Pa 1976) 2013;38:135261.

4. Allen BL Jr, Ferguson RL, Lehmann TR, et al. A mechanistic classification of closed, indirect fractures and dislocations of the lower cervical spine. Spine (Phila Pa 1976) 1982;7:1-27.

5. Stone AT, Bransford RJ, Lee MJ, et al. Reliability of classification systems for subaxial cervical injuries. Evid Based Spine Care J 2010;1:19-26.

6. Harris JH Jr, Edeiken-Monroe B, Kopaniky DR. A practical classification of acute cervical spine injuries. Orthop Clin
North Am 1986;17:15-30.

7. Aarabi B, Walters BC, Dhall SS, et al. Subaxial cervical spine injury classification systems. Neurosurgery 2013;72 Suppl 2:170-86

8. Hitti FL, McShane BJ, Yang AI, et al. Predictors of failure of nonoperative management following subaxial spine trauma and creation of modified subaxial injury classification system. World Neurosurg 2019;122:e1359-64.

9. Moore TA, Vaccaro AR, Anderson PA. Classification of lower cervical spine injuries. Spine (Phila Pa 1976) 2006;31(11 Suppl):S37-43.

10. Anderson PA, Moore TA, Davis KW, et al. Cervical spine injury severity score. Assessment of reliability. J Bone Joint Surg Am 2007;89:1057-65.

11. Divi SN, Schroeder GD, Oner FC, et al. AOSpine-spine trauma classification system: the value of modifiers: a narrative review with commentary on evolving descriptive principles. Global Spine J 2019;9(1 Suppl):77S-88S.

12. Vaccaro AR, Hulbert RJ, Patel AA, et al. The subaxial cervical spine injury classification system: a novel approach to recognize the importance of morphology, neurology, and integrity of the disco-ligamentous complex. Spine (Phila Pa 1976) 2007;32:2365-74.

13. Marcon RM, Cristante AF, Teixeira WJ, et al. Fractures of the cervical spine. Clinics (Sao Paulo) 2013;68:1455-61.

14. Da Cruz HY, Joaquim AF, Tedeschi H, et al. Evaluation of the SLICS use in the treatment of subaxial cervical spine injuries. Arq Neuropsiquiatr 2015;73:445-9.

15. Joaquim AF, Lawrence B, Daubs M, et al. Evaluation of the subaxial injury classification system. J Craniovertebr Junction Spine 2011;2:67-72.

16. Lee WJ, Yoon SH, Kim YJ, et al. Interobserver and intraobserver reliability of sub-axial injury classification and severity scale between radiologist, resident and spine surgeon. J Korean Neurosurg Soc 2012;52:200-3.

17. Whang PG, Patel AA, Vaccaro AR. The development and evaluation of the subaxial injury classification scoring system for cervical spine trauma. Clin Orthop Relat Res 2011; 469:723-31.

18. van Middendorp JJ, Audigé L, Bartels RH, et al. The subaxial cervical spine injury classification system: an external agreement validation study. Spine J 2013;13:1055-63.

19. Feuchtbaum E, Buchowski J, Zebala L. Subaxial cervical spine trauma. Curr Rev Musculoskelet Med 2016;9:496-504.

20. Kanagaraju V, Yelamarthy PKK, Chhabra HS, et al. Reliability of Allen Ferguson classification versus subaxial injury 
classification and severity scale for subaxial cervical spine injuries: a psychometrics study. Spinal Cord 2019;57:26-32.

21. Patel AA, Hurlbert RJ, Bono CM, et al. Classification and surgical decision making in acute subaxial cervical spine trauma. Spine (Phila Pa 1976) 2010;35(21 Suppl):S228-34.

22. Samuel S, Lin JL, Smith MM, et al. Subaxial injury classification scoring system treatment recommendations: external agreement study based on retrospective review of 185 patients. Spine (Phila Pa 1976) 2015;40:137-42.

23. Pizones J, Alvarez-González P, Sánchez-Mariscal F, et al. AOSpine thoracolumbar spine injury classification system. Fracture description, neurological status, and key modifiers. Spine 2013;38:2028-37.

24. Vaccaro AR, Koerner JD, Radcliff KE, et al. AOSpine subaxial cervical spine injury classification system. Eur Spine J 2016;25:2173-84.

25. Meinberg EG, Agel J, Roberts CS, et al. Fracture and dislocation classification compendium-2018. J Orthop Trauma 2018;32 Suppl 1:S1-170.

26. Schnake KJ, Schroeder GD, Vaccaro AR, et al. AOSpine classification systems (subaxial, thoracolumbar). J Orthop Trauma 2017;31 Suppl 4:S14-23.

27. Da Silva OT, Sabba MF, Lira HI, et al. Evaluation of the reliability and validity of the newer AOSpine subaxial cervical injury classification (C-3 to C-7). J Neurosurg Spin 2016;25: 303-8.

28. Aarabi B, Oner C, Vaccaro AR, et al. Application of AOSpine subaxial cervical spine injury classification in simple and complex cases. J Orthop Trauma 2017;31 Suppl 4:S24-32.

29. Urrutia J, Zamora T, Campos M, et al. A comparative agreement evaluation of two subaxial cervical spine injury classification systems: the AOSpine and the Allen and Ferguson schemes. Eur Spine J 2016;25:2185-92.

30. Du JP, Fan Y, Zhang JN, et al. Early versus delayed decompression for traumatic cervical spinal cord injury: application of the AOSpine subaxial cervical spinal injury classification system to guide surgical timing. Eur Spine J 2019;28: 1855-63.

31. Pishnamaz M, Curfs I, Uhing D, et al. Two-nation comparison of classification and treatment of subaxial cervical spine fractures: an internet-based multicenter study among spine surgeons. World Neurosurg 2019;123:e125-32.

32. Kepler CK, Vaccaro AR, Koerner JD, et al. Reliability analysis of the AOSpine thoracolumbar spine injury classification system by a worldwide group of naïve spinal surgeons. Eur Spine J 2016;25:1082-6.
33. Kwon BK, Fisher CG, Boyd MC, et al. A prospective randomized controlled trial of anterior compared with posterior stabilization for unilateral facet injuries of the cervical spine. J Neurosurg Spine 2007;7:1-12.

34. Del Curto D, Tamaoki MJ, Martins DE, et al. Surgical approaches for cervical spine facet dislocations in adults. Cochrane Database Syst Rev 2014;2014:CD008129.

35. Brodke DS, Anderson PA, Newell DW, et al. Comparison of anterior and posterior approaches in cervical spinal cord injuries. J Spinal Disord Tech 2003;16:229-35.

36. Walters BC, Hadley MN, Hurlbert RJ, et al. Guidelines for the management of acute cervical spine and spinal cord injuries: 2013 update. Neurosurgery 2013;60(CN_suppl_1):82-91.

37. Fehlings MG, Vaccaro A, Wilson JR, et al. Early versus delayed decompression for traumatic cervical spinal cord injury: results of the Surgical Timing in Acute Spinal Cord Injury Study (STASCIS). PLoS One 2012;7:e32037.

38. Joaquim AF, Patel AA. Subaxial cervical spine trauma: evaluation and surgical decision-making. Global Spine J 2014;4: 63-70.

39. Zaveri G, Das G. Management of sub-axial cervical spine injuries. Indian J Orthop 2017;51:633-52.

40. Woodworth RS, Molinari WJ, Brandenstein D, et al. Anterior cervical discectomy and fusion with structural allograft and plates for the treatment of unstable posterior cervical spine injuries. J Neurosurg Spine 2009;10:93-101.

41. Zhou F, Zou J, Gan M, et al. Management of fracture-dislocation of the lower cervical spine with the cervical pedicle screw system. Ann R Coll Surg Engl 2010;92:406-10.

42. Koivikko MP, Myllynen P, Karjalainen M, et al. Conservative and operative treatment in cervical burst fractures. Arch Orthop Trauma Surg 2000;120:448-51.

43. Isidro S, Molinari R, Ikpeze T, et al. Outcomes of halo immobilization for cervical spine fractures. Global Spine J 2019; 9:521-6

44. Reinhold M, Knop C, Lange U, et al. Reposition von Verrenkungen und verrenkungsbrüchen der unteren halswirbelsäule reduction of traumatic dislocations and facet fracture-dislocations in the lower cervical spine. Unfallchirurg 2006;109:1064-72.

45. Wang X, Yao G, Chen Y, et al. New reduction technique for the treatment of unilateral locked facet joints of the lower cervical spine: a retrospective analysis of 12 cases. Orthopade 2018;47:212-20.

46. Grant GA, Mirza SK, Chapman JR, et al. Risk of early closed reduction in cervical spine subluxation injuries. J Neurosurg 
1999;90(1 Suppl):13-8.

47. Schleicher P, Pingel A, Kandziora F. Safe management of acute cervical spine injuries. EFORT Open Rev 2018;3:347-57.

48. Khezri N, Ailon T, Kwon BK. Treatment of facet injuries in the cervical spine. Neurosurg Clin N Am 2017;28:125-37.

49. Colterjohn NR, Bednar DA. Identifiable risk factors for secondary neurologic deterioration in the cervical spine-injured patient. Spine (Phila Pa 1976) 1995;20:2293-7.

50. Gattozzi DA, Yekzaman BR, Jack MM, et al. Early ventral surgical treatment without traction of acute traumatic subaxial cervical spine injuries. Surg Neurol Int 2018;9:254.

51. Vaccaro AR, Falatyn SP, Flanders AE, et al. Magnetic resonance evaluation of the intervertebral disc, spinal ligaments, and spinal cord before and after closed traction reduction of cervical spine dislocations. Spine (Phila Pa 1976) 1999;24: 1210-7.

52. Lins CC, Prado DT, Joaquim AF. Surgical treatment of traumatic cervical facet dislocation: anterior, posterior or combined approaches? Arq Neuropsiquiatr 2016;74:745-9.

53. Ordonez BJ, Benzel EC, Naderi S, et al. Cervical facet dislocation: techniques for ventral reduction and stabilization. J Neurosurg 2000;92(1 Suppl):18-23.

54. Li H, Yong Z, Chen Z, et al. Anterior cervical distraction and screw elevating-pulling reduction for traumatic cervical spine fractures and dislocations: a retrospective analysis of 86 cases. Medicine (Baltimore) 2017;96:e7287.

55. Bunyaratavej K, Khaoroptham S. A levering technique for open reduction of traumatic unilateral locked facets of cervical spine: technical note. Asian Spine J 2011;5:176-9.

56. Shetty A, Kini AR, Muthappa D. Sub-axial cervical spine injuries: modified Stellerman's algorithm. Indian J Orthop 2011;45:261-8.

57. Fassett DR, Dailey AT, Vaccaro AR. Vertebral artery injuries associated with cervical spine injuries: a review of the literature. J Spinal Disord Tech 2008;21:252-8.

58. Biffl WL, Moore EE, Offner PJ, et al. Optimizing screening for blunt cerebrovascular injuries. Am J Surg 1999;178:51722.

59. Biffl WL, Egglin T, Benedetto B, et al. Sixteen-slice computed tomographic angiography is a reliable noninvasive screening test for clinically significant blunt cerebrovascular injuries. J Trauma 2006;60:745-51.

60. Eastman AL, Chason DP, Perez CL, et al. Computed tomographic angiography for the diagnosis of blunt cervical vascular injury: is it ready for primetime? J Trauma 2006;60: 925-9.

61. Mutze S, Rademacher G, Matthes G, et al. Blunt cerebrovascular injury in patients with blunt multiple trauma: diagnostic accuracy of duplex Doppler US and early CT angiography. Radiology 2005;237:884-92.

62. Friedman D, Flanders A, Thomas C, et al. Vertebral artery injury after acute cervical spine trauma: rate of occurrence as detected by MR angiography and assessment of clinical consequences. AJR Am J Roentgenol 1995;164:443-7.

63. Lebl DR, Bono CM, Velmahos G, et al. Vertebral artery injury associated with blunt cervical spine trauma: a multivariate regression analysis. Spine (Phila Pa 1976) 2013;38:135261.

64. Miller PR, Fabian TC, Croce MA, et al. Prospective screening for blunt cerebrovascular injuries: analysis of diagnostic modalities and outcomes. Ann Surg 2002;236:386-93.

65. Beletsky V, Nadareishvili Z, Lynch J, et al. Cervical arterial dissection: time for a therapeutic trial? Stroke 2003;34:285660.

66. Berne JD, Norwood SH. Blunt vertebral artery injuries in the era of computed tomographic angiographic screening: incidence and outcomes from 8,292 patients. J Trauma 2009; 67:1333-8.

67. Cothren CC, Biffl WL, Moore EE, et al. Treatment for blunt cerebrovascular injuries: equivalence of anticoagulation and antiplatelet agents. Arch Surg 2009;144:685-90. 